\title{
LA AMISTAD ENTRE CARLO BROSCHI FARINELLI Y EL MARQUÉS DE LA ENSENADA A TRAVÉS DE LA DIPLOMACIA EUROPEA, LA ICONOGRAFÍA, LA PROPAGANDA, LA HISTORIA Y LA LITERATURA
}

\author{
The Friendship between Carlo Broschi Farinelli and the \\ Marquis de la Ensenada through European Diplomacy, \\ Iconography, Propaganda, History and Literature
}

Daniel Martín Sáez

daniel.martins@uam.es Universidad Autónoma de Madrid. España

Fecha de recepción: 06/04/2020

Fecha de aceptación: 24/04/2020

\begin{abstract}
Resumen: En este artículo presentamos tres manuscritos custodiados en la Biblioteca Nacional de España (BNE), relativos al auge y caída del marqués de la Ensenada, identificados como Mss/5709, Mss/1962 y Mss/11038. Los tres conectan el poder del ministro con el castrato Carlo Broschi Farinelli en la época de Fernando VI, asegurando que ambos colaboraron a través de la ópera y el escuadrón del Tajo para conseguir diversos favores. Algunos historiadores, subrayado la locura de Fernando VI, han asegurado incluso que ambos formaron parte de un «equipo terapéutico» destinado a impedir, a través de los festejos, que los reyes obstaculizaran los proyectos de gobierno. Esto ha dado lugar a una verdadera mitología en torno a la amistad entre Ensenada y Farinelli, pero la realidad es mucho más compleja. Acudiendo a la correspondencia cortesana y otras fuentes -la mayoría de ellas, desconocidas hasta ahora en los estudios farinellianos-, intentaremos aclarar el alcance de esta amistad.
\end{abstract}

Palabras clave: Farinelli; Ensenada; manuscritos; cartas; BNE.

Abstract: In this article I present three manuscripts kept in the National Library of Spain (BNE), relating to the rise and fall of the Marquis of Ensenada, identified as Mss/5709, Mss/1962 and Mss/11038. The three sources connect the power of the minister with the castrato Farinelli, assuring that both collaborated through opera and the Tajo squadron to obtain some favors. Some historians underline the madness of Ferdinand VI assuring that they both formed part of a "therapeutic team» 
aimed at preventing the kings, through the festivities, from obstructing the government projects. This has given rise to a true mythology around the friendship between Ensenada and Farinelli, but the reality is much more complex. Using court correspondence and other sources, most of them unknown until now in the Farinelli studies, we will try to clarify the scope of this friendship.

Keywords: Farinelli; manuscripts; letters; Ensenada; BNE.

SUMARIO: 1. Introducción. 2. Detalles generales de los tres manuscritos de la Biblioteca Nacional. 3. El contenido de los manuscritos y el mito del «equipo terapéutico». 4. Farinelli cortesano: diplomacia y leyenda de la primera superestrella. 5. La "amistad» entre Farinelli y Ensenada a través de la diplomacia europea. 6. Ensenada y Farinelli: la mirada especular de Jacopo Amigoni. 7. Nuevos libelos y la correspondencia con Bernardo Tanucci. 8. Melancolía y dominación: una imagen mitológica. 9. Fuentes (no editadas). 10. Referencias bibliográficas. 11. Anexo.

\section{INTRODUCCIÓN}

En 1878, Antonio Rodríguez Villa publicó su canónico «ensayo biográfico» sobre Zenón de Somodevilla y Bengoechea, más conocido como el marqués de la Ensenada, donde sacó a relucir por primera vez numerosos documentos sobre el famoso ministro del siglo XVIII. Uno de ellos coincide en su contenido con al menos tres manuscritos custodiados en la Biblioteca Nacional de España (BNE): Mss/5709, Mss/1962 y Mss/11038. En los tres casos, se incluye una breve biografía del marqués de la Ensenada de unas veinte cuartillas, seguida de una serie de objetivos políticos y otra de ataques enumerados contra el ministro (otras cuarenta cuartillas), todo ello dirigido a criticar su carrera política hasta su caída en 1754.

Algunos fragmentos de esta triple fuente han despertado especial interés entre los musicólogos, pues citan varias veces al cantante Carlo Broschi Farinelli, al que siempre se refieren como «el capón», nombre castizo con que los españoles se referían a los castrati (Medina, 2011). El breve texto otorga al músico un papel crucial en la vida cortesana por su cercanía a los reyes, tanto a Felipe $V$ e Isabel de Farnesio como a Fernando VI y Bárbara de Braganza, llegando a sostener que el marqués necesitó su ayuda para ser nombrado ministro. Se trata, además, de un singular testimonio sobre la importancia política de la ópera en la corte de Fernando VI, empeño cultural que se toma como una labor de Farinelli, interpretada como una excusa para controlar a los reyes y conseguir dinero por medio de Ensenada. Un lugar similar ocupa el denominado escuadrón del Tajo, las famosas embarcaciones de Fernando VI y Bárbara de Braganza durante sus estancias veraniegas en el Palacio de Aranjuez, todo lo cual habría servido a Ensenada y Farinelli para ascender en la corte.

Rodríguez Villa no indicó claramente la naturaleza de sus fuentes, refiriéndose de un modo genérico a un "papel que circuló por muchas provincias de España», para transcribir a continuación varios fragmentos de papeles contra el marqués conservados entonces en la Real Academia de la Historia (1878, p. 225). Una de esas 
fuentes fue utilizada, ese mismo año de 1878, por el musicólogo Francisco Asenjo Barbieri en su prólogo a la Crónica de la ópera italiana en Madrid desde el año 1738 hasta nuestros días de Luis Carmena y Millán, destacando las menciones a Farinelli y afirmando que lo había conocido a través de su «querido amigo» Rodríguez Villa (Carmena y Milán, 1878, p. Iv). Sin embargo, ninguno de los tres manuscritos ha sido publicado hasta ahora, y sólo uno de ellos ha sido citado en conexión con Farinelli y el marqués de la Ensenada: el Mss/11038 (Gómez Urdáñez, 1996, p. 106). Los otros dos han pasado inadvertidos, aunque presentan algunas divergencias de contenido dignas de interés, mostrando que las ideas aquí contenidas gozaron de cierta difusión.

Para mayor claridad, hemos incluido una transcripción completa de la biografía inicial, incluyendo las menciones a Farinelli del resto de cuartillas e indicando las divergencias entre las tres fuentes (véase el Anexo). A través de su estudio, y acudiendo a otras múltiples fuentes, sobre todo diplomáticas, la mayoría de ellas no consideradas hasta ahora en los estudios farinellianos, intentaremos averiguar cuál fue el alcance de esta singular «amistad» entre el músico y el ministro, donde lo histórico, lo político y lo legendario se mezclan sin remedio.

\section{DETALLES GENERALES DE LOS TRES MANUSCRITOS DE LA BIBLIOTECA NACIONAL}

El manuscrito Mss/5709, como el Mss/1962, nos ofrece por primera vez un título para estos manuscritos, desvelando su intención difamatoria: «Relacion. $Y$ ultima desgracia de la monarquia de España baxo él Govierno de Don Zenòn Somodevilla, Marqués de la Ensenada, que durò de el año de 1743 que por muerte de Don Joseph del Campillo entrò a los manejos de la Real Hacienda de Indias, Guerra y Marina, hasta el 21 de Julio de 1754, que fue depuesto de todos sus Empleos, y desterrado a la Ciudad de Granada», ocupando un total de 27 folios, de los cuales los 11 primeros se centran en su caída de un modo biográfico. Estos folios los transcribimos de forma íntegra, para que se pueda apreciar el contexto en que se cita a Farinelli en conexión con la política ensenadista. Después, el texto retrocede súbitamente hasta la Paz de 1748, parte que incluye una breve mención a Farinelli, a la cual sigue una serie de diez objetivos marcados por la corte, que contrastan con un listado de veintiún errores cometidos por Ensenada, donde Farinelli aparece de nuevo en un par de ocasiones. En estos tres últimos casos, transcribimos solamente los párrafos íntegros donde aparece Farinelli, dado que el manuscrito mezcla diversas acusaciones ajenas a nuestro interés.

El Mss/1962, por su parte, contiene numerosos «papeles referentes al Marqués de la Ensenada y otros documentos», según el título de la Biblioteca Nacional, de los cuales nos interesan los folios 92-127, donde se encuentra el manuscrito 
titulado "Sucita relacion. Y ultima desgracia de la Monarquia de España, vaxo el Govierno de Don Zenon Somodevilla, Marques de la Ensenada, que durò desde el año de 1743, que por muerte de Don Joseph de el Campillo entrò a los manejos de la Real Hacienda, Indias, Guerra, y Marina, hasta 21 de Julio de 1754, que fue depuesto de todos sus Empleos, y desterrado a la Ciudad de Granada». Este cambio de título es la única divergencia de contenido respecto al anterior, aunque enumera veintidós errores en lugar de veintiuno, al dividir el décimo error en dos partes. La caligrafía es la más cuidada de las tres.

El Mss/11038, finalmente, se titula «Papeles varios» e incluye papeles muy diversos, destacando los relativos a Ensenada, que incluyen el documento que nos ocupa en los folios 191-226 (seguimos la numeración en lápiz), bajo el encabezado de «Barios papeles en que esta recopilada la Vida, empleos, Privanza, Caida, y Destierro del Marques de la Ensenada». El cariz político de la colección se puede observar leyendo las «decimas, octabas y sonetos» contenidas más adelante, donde se define a Ensenada como "el Atila que a España / tiranizaba» (BNE, Mss/11038, f. 287). Curiosamente, sin embargo, la crítica al marqués es menos fuerte en algunos puntos, incluyendo al principio varios datos sobre los orígenes del marqués que no aparecen en el resto de manuscritos y que nada tienen de difamatorio. También se producen algunas omisiones significativas. Por ejemplo, no contiene una mención a las "pueriles diversiones» organizadas por Ensenada y en lugar de afirmar que, en uno de sus empeños, Ensenada trabajó poco, aparece un paréntesis benevolente: "(dicen) que trabajó poco». Aunque la divergencia más significativa quizá sea cuando se afirma que Ensenada trabajó en los oficios de Marina de Cádiz «sin hacer pie fijo en ella, ni en otra alguna, huyendo siempre de toda sujeción y fatiga»; en su lugar, este manuscrito afirma que "su espíritu, ocupado en grandes ideas» le llevó por otros derroteros. En nuestra transcripción hacemos constar entre corchetes estas divergencias. Aparte de eso, también hay un fragmento final que no aparece en los otros textos, donde se narra la caída de otros ensenadistas como Ordeñana y Mogrovejo y se indica como fecha de redacción el 20 de agosto de 1754, fecha que no aparece en los otros dos manuscritos.

En ningún caso hemos podido hallar la autoría del texto. Aparte de los títulos y el citado cambio en la introducción de Mss/11038, es obvio que los tres han sido copiados de una fuente común, seguramente difundida de forma anónima como un libelo. Además, los copistas son diferentes, como se puede comprobar comparando las caligrafías (véase la Tabla 1). Por las razones antedichas, las diferencias son más evidentes en los dos primeros manuscritos (Mss/5709 y Mss/1962), salvo por los cambios en la ortografía y la sintaxis. 
BN Mss/5709, f. 2.

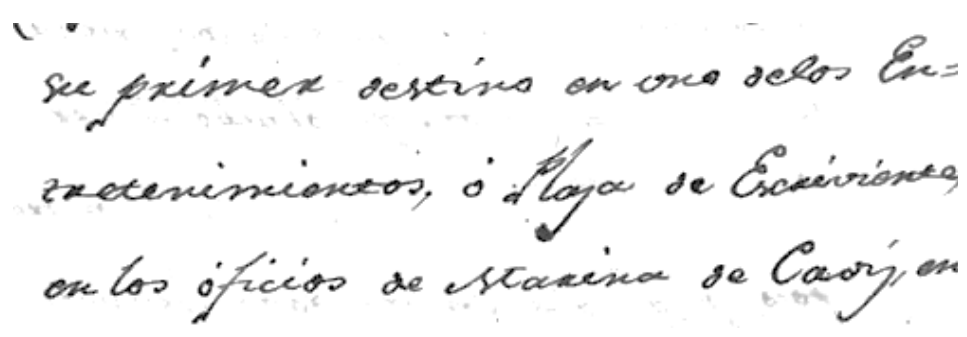

BN Mss/1962, f.92.

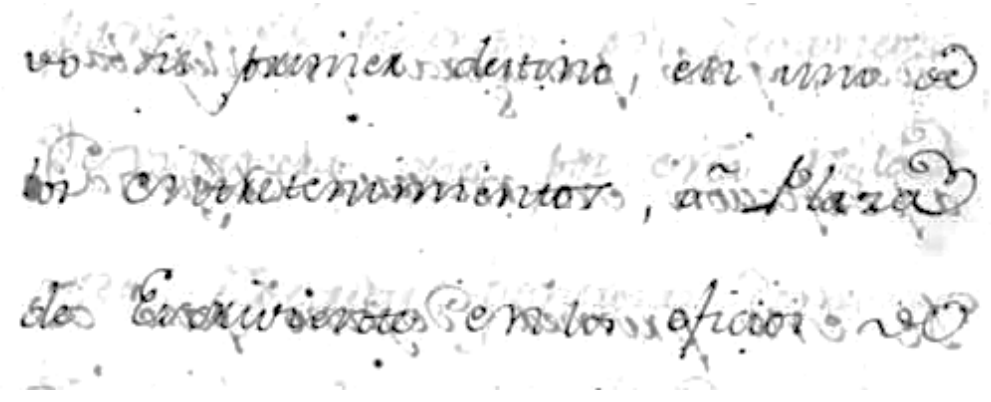

BN Mss/11038, f. 200.

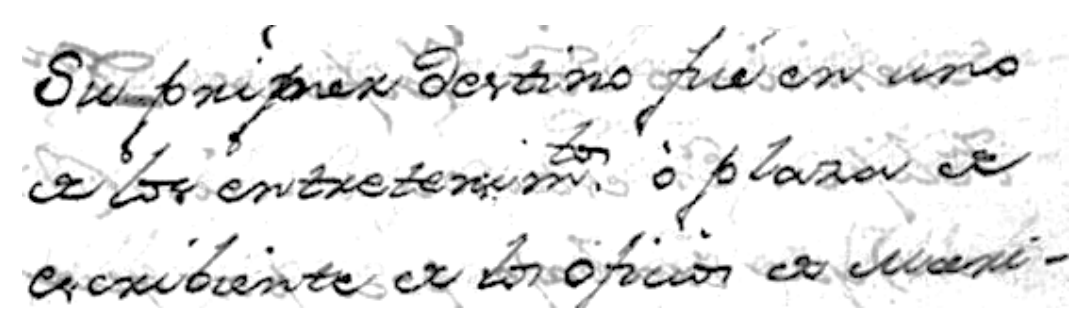

Tabla 1. Comparación de las caligrafías de los manuscritos Mss/5709, Mss/1962 y Mss/11038 de la Biblioteca Nacional de España

Por lo que se refiere a la fecha de redacción, como hemos visto, sólo el Mss/11038 indica una posible fecha en los días cercanos a la caída del marqués. Respecto a las otras copias, podemos admitir un terminus post quem en 1754, aunque nada impide que fueran copiados con posterioridad, pero no más allá de 1759, dado que ambos se refieren a la "última desgracia de la monarquía de España». Curiosamente, el autor del manuscrito se refiere siempre a Farinelli en pretérito imperfecto. Primero afirma que «era sujeto de capacidad y no se apartaba del lado de la reina»; luego, que "hacía venir de Italia a las cantarinas más célebres». Alrededor de ambas afirmaciones hay otra decena de verbos en pasado, que nos permiten establecer, aunque sea como mera hipótesis, la fecha de 1759 como terminus ante quem, cuando Carlos III prescindió del cantante. 


\section{EL CONTENIDO DE LOS MANUSCRITOS Y EL MITO DEL «EQUIPO TERAPÉUTICO"}

En los tres manuscritos observamos un claro interés por criticar no sólo a Ensenada, sino también las costumbres de la corte. Ensenada aparece como un embaucador centrado en ganarse el favor de "las damas» a través de obsequios y "devaneos», con el objetivo de obtener un «lugar en la confusión de la corte, donde los actos exteriores y la lisonja» tendrían preferencia frente "a la verdadera entidad y el mérito». El ascenso de Ensenada se liga así a tres personajes: José Campillo y Cossío, ministro de Felipe V; Laura Castelví y Coloma, marquesa de Torrecuso y camarera mayor de la reina Isabel de Farnesio, y Carlo Broschi Farinelli. Los tres sirven como ejemplo del modo en que Ensenada habría ascendido a través de sus contactos:

1. En primer lugar, siendo secretario del Almirantazgo del infante Felipe [desde 1736], ocupación en la que se nos dice que "trabajó poco», Ensenada se habría ganado el favor del ministro de Felipe V, José Campillo. Esto habría ocurrido hacia 1741, un año después de la muerte de Carlos VI, en el contexto que daría lugar al Segundo Pacto de Familia. El panfleto asegura que Ensenada empezó a interesarse por los planes de Campillo durante una enfermedad, momento que aprovechó para visitarle y sonsacarle información reservada.

2. En segundo lugar, habría hecho circular la idea de que poseía esa información a través de la marquesa de Torrecuso, haciendo saber así a la corte que podía continuar con sus planes si el ministro fallecía, como ocurrió en 1743 , cuando la propia marquesa de Torrecuso habría convencido a Isabel de Farnesio para contratar a Ensenada.

3. En tercer lugar, Ensenada se habría ganado el favor de Farinelli, cuya amistad habría "comprado a buen precio» durante el reinado de Fernando VI. Gracias al cantante habría conseguido acceder a la reina, Bárbara de Braganza, y derrocar con su ayuda al que había sido secretario de Estado con Felipe V, Sebastián de la Cuadra y Llarena, el marqués de Villarías. Tras conseguir el puesto, Ensenada habría acudido recurrentemente a Farinelli, que «conseguía la gracia de los reyes a través de sus operarios festejos» y "lisonjeando a la pobre Reina», que «bajo los influjos del capón, vivía engañada». Los libelos hablan de dos favores mutuos obtenidos de este modo: primero, Farinelli habría convencido a los reyes para que otorgaran a Ensenada el Toisón de Oro, a lo que el propio ministro habría respondido solicitando la Orden de Calatrava para Farinelli, pagándole además (a cuenta de la corona) una suma de dinero correspondiente a los bienes perdidos en Inglaterra.

Los manuscritos atribuyen otras maquinaciones a Ensenada, que a través de «mercedes», "gratificaciones» y "pensiones secretas» logró acercarse "a todos los demás sujetos que servían cerca de los reyes», formando "un Partido» y situando 
a sus amigos en lugares de responsabilidad, que le servían así como espías «para entender las inspiraciones, y conversaciones de los reyes», entre los cuales cita a Agustín Pablo Ordeñana y Goxenechea, al que nombró oficial mayor de la Secretaría de Estado del infante Felipe. Los manuscritos aseguran que Ensenada hacía «ensayar en su casa» las óperas "para que los reyes entendiesen cuanto se esmeraba en dar gusto», y que contribuyó a las famosas embarcaciones del Tajo acometiendo obras en el río para hacerlo navegable, «suspendiendo el acceso de las aguas y haciendo otras obras de suma costa para la navegación, para lo cual se trajo de los puertos marinería que hiciese las faenas correspondientes».

Basándose en estos manuscritos, algunos estudiosos han mantenido que Ensenada y Farinelli utilizaron las óperas del Retiro y las fiestas de Aranjuez para mover la voluntad de los reyes. El historiador José Luis Gómez Urdáñez ha llegado a afirmar que la corte de Fernando VI se entregaba a «fiestas y músicas» debido a la «necesidad de que el rey y la reina se divirtieran y no llegara la temible melancolía», siendo «esencial» en este punto «la inteligencia de Farinelli» (Urdáñez, 2002, p. 81). Concretamente, Urdáñez asegura que el «asalto a la reina» por parte de Ensenada se hizo a través del músico, con quien formó una suerte de «equipo terapéutico» destinado a "tranquilizar al rey», contribuyendo así a "lograr la firma del rey para dar luz verde a los planes de sus ministros» (Urdáñez, 2017, pp. 71-72). El parecido de este relato con el "mito de entrada», según el cual Farinelli vino a España en 1737 para curar con su canto la melancolía de Felipe V, no es casual. Se trata de un relato difamatorio nacido en el mismo contexto histórico de propaganda y habladurías en que surgió, precisamente, el mito davídico del rey curado por la voz del castrado (Martín Sáez, 2018).

\section{FARINELLI CORTESANO: DIPLOMACIA Y LEYENDA DE LA PRIMERA SUPERESTRELLA}

Nuestra imagen sobre Farinelli está atravesada por todo tipo de habladurías y leyendas, especialmente en el caso de España, donde la imagen de la superestrella se mezcla con el mito de un cantante capaz de influir sobre los reyes con su música. Como sabemos, esta imagen estuvo determinada por los conflictos con Inglaterra, desde la Guerra del Asiento hasta la propia caída de Ensenada. Farinelli llevaba tres años trabajando en Londres cuando abandonó el país para establecerse en Madrid en 1737, causando un conflicto diplomático que la prensa aprovechó para incitar la guerra contra España utilizando la fama del castrato. Solo en el siglo XVIII conocemos más de trescientas noticias sobre el cantante publicadas en más de sesenta periódicos ingleses, muchas de ellas dedicadas a su paso por España, que han determinado nuestra imagen del cantante (Martín Sáez, 2019). 
Una situación parecida se puede reconstruir en la diplomacia europea, tanto española como inglesa, austriaca, francesa e italiana, donde casi siempre que se habla de Farinelli es para citar su cercanía con los reyes y su amistad con Ensenada. El embajador de Londres en Madrid, Benjamin Keene, nos ofrece una clara imagen de lo primero en una carta del 20 de febrero de 1749, donde narra su asistencia a una de las óperas organizadas por Farinelli en el Coliseo del Buen Retiro:

Apenas me senté la pasada noche en la ópera, sus Católicas Majestades me enviaron el libreto en manos de Farinelli. Imagina cómo contemplaron este signo de distinción mis colegas de palco ${ }^{1}$.

Esta aparición de la superestrella como una suerte de representante musical del poder político no era ajena a su conexión con Ensenada. En otra carta fechada cinco días después, el embajador llega a sostener que Farinelli, al que considera «una llave al secreto de este país», es quien lleva las riendas de la relación:

Farinelli es más que mi amigo, y jura que ama la nación [inglesa] y me servirá. Su valor está en que se hace depender del hombre que depende enteramente de él, pero no me sorprende que alguien de su rango y profesión no se atreva a ser más. Percibirás que por ese hombre me refiero al Señor de la Ensenada. $Y$ ahora tienes una llave al secreto de este país...².

No es casualidad que la propaganda inglesa contra Farinelli y Ensenada coincida en el tiempo. Además de su amistad, el cantante y el ministro son dos figuras poderosas y reconocidas en Europa, que han logrado ascender pese a sus orígenes humildes

${ }^{1}$ «The next night I was no sooner seated at the opera but their Cahtolic Majesties sent me the libretto by the hands of Farinelli. Judge how my confreres in the box lokt upon this mark of distinction» (Keene, 1933, p. 95).

2 «Farinelli is much my friend, and wears he loves the nation and will serve me. The worth of him is that he makes himself a dependent upon the man who entirely depends upon him, but I am not surprised that one of his rank and profession should not dare to be greater. You will perceive I mean Mr. Ensenada by the man I mention. And you have now a key to the secret of this country, which for Godsake keep to yourselves. Farinelli has been with me since I wrot thus far. I have let him see the flourishing state of England, the strength and security of the ministry, the personal regard the King has had, even during the war, for their Catholic Majesties, that the Queen of Spain would know the King's sentiments for her in particular by reflecting with eher own good sense upon His Majesty's friendship for the King her father, and for the unheard of and unprecedented marks of assistance and attachment His Majesty has shwen [sic] to the family of her Mother, both of them examples of the value of a strict allyance with his Royal Person. My friend [Farinelli] has desired me to make his humble compliments to my Lord Duke of Newcastle, and to assure his Grace that he is a true Englishman». Carta del 25 de febrero de 1749 enviada a Andrew Stone (Keene, 1933, p. 98). 
y a los cuales atraviesan, en distinto grado, los conflictos con Inglaterra. Es importante remarcar que su amistad era conocida en las cortes europeas. Baste recordar las cartas del secretario de la embajada de Parma, Juan Rice de la Calzada, enviadas el 28 y el 29 de abril de 1753 al duque de Huéscar, donde narra cómo el director de Hacienda de la corte parmesana presumía de tener a un yerno suyo en España que le facilitaba la confianza del marqués de la Ensenada, precisamente por medio de Farinelli (Morales, 2007, pp. 62-63). Este yerno resulta ser el banquero florentino Francesco Maria Ridolfi, a quien el cantante aloja en su casa, sirviéndole de mediador en diversos asuntos (Broschi Farinelli, 2000, p. 309 y p. 160) y ayudándole con la correspondencia ${ }^{3}$.

La «amistad» entre el ministro y el cantante fue, de hecho, más profunda de lo que pensaba Keene, como él mismo pudo constatar en los meses cercanos a su caída. El 17 de mayo de 1754, por ejemplo, le escribe al duque de Newcastle contándole que el conde de Migazzi, embajador de Austria, ha intentado convencer a Farinelli de la política pro-francesa de Ensenada, a lo que el cantante respondió hablando con el propio Ensenada, que le habría convencido de que «alimenta a los franceses con meras apariencias, siendo en el fondo su enemigo». Keene teme con ello que Ensenada «se apoye en el poderoso amigo que hasta ahora le ha apoyado con su majestad católica», en referencia a Bárbara de Braganza ${ }^{4}$.

Informaciones de esta índole llegaron, de un modo u otro, a la prensa, como lo harían después a la historiografía y la literatura, dando lugar a todo tipo de especulaciones. La correspondencia diplomática, de hecho, raramente pasa de la mera especulación, algo sin duda determinado por el secretismo del poder monárquico y sus privados. Así lo muestra la propia ambigüedad mostrada por Farinelli en algunos momentos. Dos años después de la caída de Ensenada, el 16 de julio de 1756, Keene relata un encuentro del duque de Duras ${ }^{5}$, embajador francés en Madrid, con el cantante, en el que Farinelli dio muestras de su discreción. La carta es además un testimonio único sobre la importancia de los festejos de Aranjuez y, en concreto, de las embarcaciones del Tajo:

${ }^{3}$ Así se puede constatar en las cartas de Metastasio, que el 24 de marzo de 1753 se refiere a la carta que le ha enviado Farinelli «di carattere del signor Ridolfi» (Metastasio, 1954, p. 803). Lo mismo ocurre con las cartas escritas a Torrepalma conservadas en el Archivo Histórico de la Nobleza, BAENA, C. 395, D. 614, lo que muestra que Ridolfi pudo tener este cometido hasta 1758.

${ }^{4}$ "Count Migazzi made the strongest and most able representations to Farinelli, shewing [sic] him the injury he did to the princess, to whom he was so much obliged; his aversion to her good, and that of her cousin the empress queen, if he supported a minister so evidently inclined and engaged to France as Ensenada. Farinelli seemed to yield a little at first; but having had time to see Ensenada, and acquainted him with what Migazzi had said, he persuaded the poor musician of his error: nothing can take it out of his head, that Ensenada for private views feeds the french with appearances only, and that he is at heart their enemy. It is feared, that Ensenada will support himself by the powerful friend who has hitherto supported him with her catholic majesty» (Coxe, 1813, p. 149).

${ }^{5}$ Cf. Carta de Duras a Antoine Louis Rouillé, conde de Jouy, Secretario de Estado de la Marina, Archives Nationales, Affaires étrangères (Paris), AE/B/I/788, fol. 289-292v. 
La embarcación del Tajo, dirigida por Farinelli, daba al embajador [el duque de Duras] y la embajadora franceses la oportunidad de acercarse a él, dado que solía llegar a la embarcación real cerca de una hora antes que sus católicas majestades. Duras empleaba ese tiempo para suplicar, encarecer y hacer ofertas a Farinelli, pero su respuesta, según asegura el conde Migazzi, siempre fue responderle que él era un músico, no un político ${ }^{6}$.

El embajador francés sabía que esto no era cierto. Poco antes de la caída de Ensenada él mismo había sido conocedor del intento de Huéscar, Keene y Ricardo Wall por ganarse el favor de Farinelli contra el ministro (Gómez Urdáñez, 1999, p. 239). Todos sabían que Farinelli era mucho más que un músico, como lo había sido desde su entrada en la corte de Felipe $V$, cuando el propio cantante aseguraba que su «mérito» no era "ser considerado Farinelli, sino Farinelli embajador». ${ }^{7}$ Duras no era el único que intentaba acercarse al cantante. Bernardo Tanucci llega a afirmar del propio Migazzi que «fue tan adulador en España, que le ponía el orinal a Farinelli cuando estaba enfermo", algo que le habría servido después para ser nombrado "Arzobispo y Cardenal ${ }^{8}$. Las cortes europeas sabían que Farinelli había contribuido a lograr otros ascensos como este, aunque su poder fuera más limitado en cuanto a las decisiones de gobierno ${ }^{9}$.

La propia caída de Ensenada en 1754 también estuvo marcada por este contexto diplomático, donde la propaganda y la rumorología se retroalimentan sin cesar. Uno de los testimonios más interesantes apareció en octubre en Le Courrier, informando sobre una supuesta paralización de «los magníficos espectáculos» organizados por Farinelli:

${ }^{6}$ "The embarkation on the Tagus, which is directed by Farinelli, gave both the french ambassador and ambassadress an opportunity of intruding upon him, as he generally comes to the king's barge near an hour before their catholic majesties. Duras employed this time in begging, caressing, and making offers to Farinelli; but his answer, as he assures count Migazzi, has constantly been, that he was a musician, not a politician" (Coxe, 1813, pp. 180-181).

7 Carta de Farinelli a Pepoli del 16 de febrero de 1738 (Broschi, 2000, p. 144). El 23 de agosto de ese año añade, además, que es considerado "como un hijo» por la familia real, gozando de una insólita libertad de movimientos (p. 152).

8 «Che dice V. E., che dice il Signor Ambasciatore del Proteo Migazzi, che dopo aver tanto adulato in Spagna, che porgeva l'orinale a Farinello malato, divenne Arcivescovo e Cardinale, e volento ora tanta Ungheria si è venduto ai Gesuiti e viene a Roma, fiaccola e incendio della Francia, per vendicare li Gesuiti?» (Tanucci, 2000, p. 404).

9 Un testimonio sobre las posibles limitaciones de Farinelli lo ofrece de nuevo Keene en su correspondencia con el duque de Newcastle. El 30 de agosto de 1752, ante la insistencia del duque por acercarse a la reina a través de Farinelli, Keene le contesta que «es mejor utilizar los pequeños canales para los pequeños asuntos» (Keene, 1933, p. 100, n. 2). 
Las Cartas de España dicen que el exilio del Marqués de la Ensenada ha puesto fin a los magníficos espectáculos y las galantes celebraciones que son tan admiradas por la Corte como por los extranjeros. No había nadie en el aniversario del nacimiento del Rey. El Caballero Farinelli, que lo dirigía todo, y cuyo genio para las decoraciones es tan conocido, preguntó un tiempo antes si no sería apropiado trabajar en los preparativos para una nueva ópera, y le dijeron que S. M. no había decidido nada al respecto. Desde entonces, hemos sabido sobre las representaciones realizadas al Rey que cada año se gastan inmensas sumas de dinero en este tipo de espectáculos, y que S. M. ha decidido eliminarlas. Se estima que cada representación de Ópera cuesta hasta 200 mil piastras. La Didone abandonada, que ha sido tan admirada, costó más de 300 mil piastras. Pero si por un lado estas representaciones causan tan grandes gastos, el Marqués de la Ensenada no cree que tenga que ahorrar nada a los placeres de Su Majestad Católica, y está convencido de que este tipo de gasto es también beneficioso para muchas personas empleadas allí, lo que hace que el dinero circule entre el público ${ }^{10}$.

Obviamente, esto no se ajusta a la realidad. Las óperas continuaron el resto del año. Para celebrar el cumpleaños del rey se estrenó la ópera L'eroe cinese de Metastasio y Conforto, sin que haya ninguna diferencia en la regularidad con que se hicieron representaciones respecto al año anterior o el siguiente. En el caso de los paseos por el Tajo, como hemos visto, las fiestas no habían hecho más que empezar.

Otro ejemplo del modo en que la información se tergiversa y se transforma en una imagen mitológica, destinada en este caso a encumbrar al personaje, la encontramos en la primera biografía de Farinelli, escrita por Giovenale Sacchi, esta vez desde Italia:

Farinelli no previó ni un solo día la caída del célebre ministro Ensenada; así, golpeado por la súbita revolución, temió que la estrecha amistad y adhesión que siempre había conservado inviolablemente al ministro le pudiera ser imputada; por

10 «Les Lettres d'Espagne portent que l'exil du Marquis de la Ensenada a fait cesser ces magnifiques spectacles \& ces fètes galantes qui faisoient également l'admiration de la Cour $\&$ de tous les étrangers. II n'y en a point eû le jour de l'anniversaire de la naissance du Roi. Le Chevalier Farinelli, qui avoit la direction de tout, $\&$ dont le génie pour les décorations est si connu, demanda quelque tems auparavant s'il n'étoit pas convenable de travailler aux préparatifs d'un nouvel Opera, \& on lui répondit que S. M. n'avoit rien décidé à cet égard. On a sçu depuis que sur les représentations qu'on a fait au Roi qu'il se dépensoit chaque année des sommes immenses pour ces sortes des Spectacles, S. M. s'est déterminée à les supprimer. On fait compte que chaque Opera que l'on représentoit coûtoit jusqu'a 200 mille piastres. Celui de Didon abandonnée, qu'on a tant admiré, a coûté plus de 300 mille piastres. Mais si d'un côté ces réprésentations occasionoient de si grands fraix, le Marquis de la Ensenada qui ne croyoit devoir rien épagner pour les plaisirs de L. M. Cath. étoit persuadé que ce genre de dépense étoit en même tems profitable à quantité de personnes qu'on y employoit, ce qui faisoit circuler l'argent dans le public» (Le Courrier, no LXXXVI, du Vendredi 25 Octobre 1754, p. 345). 
eso se puso rápidamente a los pies del rey, el cual le confortó diciéndole que el caso de Ensenada no tenía nada que ver con él (Sacchi, 1784, p. 45).

Como veremos, esto no sólo contradice las cartas de los embajadores, sino también al propio Ensenada, que escribió una carta a Farinelli el 15 de junio para solicitar a la reina su dimisión, comenzando con esta frase: «ya $V m$. habrá conocido la inquietud de mi ánimo y también la causa» (Rodríguez Villa, 1878, p. 188) ${ }^{11}$. La biografía de Sacchi tiene un interés apologético desde la primera hasta la última línea, subordinado a una intención moralizante, así que resulta tan poco creíble como la propaganda inglesa o los libelos madrileños.

\section{LA "AMISTAD" ENTRE FARINELLI Y ENSENADA A TRAVÉS DE LA DIPLOMACIA EUROPEA}

La íntima conexión de Farinelli con los reyes encaja sin duda con las fuentes conservadas, como también su vinculación con el ministro y su perfil político (González Caizán, 2004), que se puede corroborar en las cartas que Metastasio dirige a Farinelli y en la propia correspondencia de Ensenada, pero también en la diplomacia europea. Ensenada se refiere al cantante en numerosas ocasiones como su "amigo», aunque no hemos de olvidar que en tal noción se mezclan lo personal y lo cortesano, como hemos visto en el caso de Duras. Esto es evidente en la carta del 6 de agosto de 1747 que Ensenada escribe a Huéscar: «Esté Vm enamorado de Farinello, pues sus cualidades deben ser envidiadas del hombre de mayor distinción y téngalo por su verdadero amigo» (Ozanam y Téllez Alarcia, 2010, p. 290). Como hemos visto, también Keene sostenía que Farinelli era "más que su amigo», y lo mismo podemos observar en su correspondencia con el conde de Torrepalma, embajador español en Viena, ${ }^{12} \mathrm{y}$ con el duque de Leeds (McGeary, 2002). Pero la correspondencia destaca especialmente su amistad con Ensenada. Además del citado director de Hacienda de la corte parmesana, también el embajador francés en España, François Marie de Villers-la-Faye, conde de Vaulgrenant, sitúa a Farinelli como mediador para acceder al ministro en una carta fechada el 25 de mayo de $1750^{13}$.

Las cartas de Ensenada demuestran la centralidad de Farinelli en la corte y su confianza en que cuenta con su respaldo ante los reyes, como escribe el 17 de septiembre

11 «Aunque soy nada», continúa después, «amo mi reputacion como si fuese algo» y «acudo á la amistad y cariño de Vm., y á que le correspondo con todo mi ánimo, para que busque la ocasión de conseguir de nuestra Ama con su gracia el permiso de que yo, cuándo y cómo le parezca á S. M., haga dimision de mis empleos» (p. 189).

12 Véase la correspondencia conservada en el Archivo Histórico de la Nobleza, BAENA, C. 395, D. 614, f. 2.

${ }^{13}$ Carta a Antoine Louis Rouillé, conde de Jouy, Secretario de Estado de la Marina, Archives Nationales, Affaires étrangères (Paris), AE/B/I/786, ff. 351-352v. 
de 1747 a Huéscar: «He tenido siempre por hombre de fiar a Farinello y le he tratado como tal y me paga si es mi amigo» (Ozanam y Téllez Alarcia, 2010, p. 312). Que los tres colaboraron parece deducirse de otra carta de Ensenada del 1 de febrero de 1748, en la que indica a Huéscar que está en deuda con Farinelli, ya sea porque éste ha mostrado su disposición genérica a ayudar o porque, de hecho, se traen algo entre manos: «Esté Vm en que a Farinello debe una amistad muy particular y él está en que Vm no lo ignora» (Ozanam y Téllez Alarcia, 2010, p. 380). El propio Huéscar lo agradece el 16 de febrero de ese año: "Agradezca Vm a Farinello su buena amistad» (Ozanam y Téllez Alarcia, 2010, p. 385). Mientras tanto, Ensenada había enviado otra carta a Huéscar el 12 de febrero, donde se refería a Farinelli como «buen amigo, honrado, prudente y generoso» (Ozanam y Téllez Alarcia, 2010, p. 383), a lo que Huéscar responde el 2 de marzo: «Creo y conozco que Farinello merece la definición que $\mathrm{Vm}$ hace en llamarle buen amigo, honrado y generoso» (Ozanam y Téllez Alarcia, 2010, p. 389).

También tenemos constancia de que Farinelli hizo de mediador entre Ensenada y los reyes. Así lo demuestra un «billete» escrito por Farinelli en julio de 1749, encontrado por Rodríguez Villa, donde el cantante ordena a Ensenada, de parte del rey, que acalle las habladurías provenientes de la corte de la reina viuda, según las cuales se habría comentado con regocijo que, al no tener Fernando VI descendencia, antes o después gobernaría el hijo de Isabel de Farnesio, como de hecho acabaría ocurriendo. El siguiente fragmento constituye una prueba única del tipo de información íntima a la que tenía acceso Farinelli:

Manda el Rey que por el primer parte que hubiere, escriba a [Annibale] Scotti diciéndole que consta que en aquel Sitio no se habla ni procede con el respeto que es debido á esta Córte; que se cree que la Reina viuda no sepa nada desto, pues si lo supiese, no se duda tomaria todas las precauciones para impedirlo, y que él procure hacerlo ó por sí, ó diciéndolselo á ella, para deste modo evitar que el Rey tome alguna determinacion fuerte, lo cual sería de sentimiento á la Reina; que esto se lo escribe Vd. en confianza para que se ataje esto y se contenga esa gente (Rodríguez Villa, 1878, p. 370).

También Farinelli parece haberse referido como un «amigo» a Ensenada, como se puede observar en la carta que Metastasio dirige al cantante el 13 de junio de 1750:

a mi veneradísimo señor marqués de la Ensenada decidle que estoy sobrepasado por las generosas expresiones que me llegan de él a través vuestro, y que reconozco en ellas una gran parte de las bellas cualidades de su corazón. En resumidas cuentas, habéis nacido para gustar de cuanto puede dar de dulce la humanidad: la cercanía de un amigo de tal calibre no es la última delicia de la vida ${ }^{14}$.

14 «Al mio veneratissimo signor marchese Ensenada dite ch'io sono sopraffatto dalle generose espressioni che mi vengono da lui per il vostro mezzo, e che riconosco in quelle una gran 
Una carta del 3 de enero de 1750 explica las menciones a Ensenada en la correspondencia de los famosos "gemelos». Metastasio se refiere allí al encargo que le hizo Farinelli varios meses antes, que consistía en conseguir una serie de caballos para la caballeriza real. ${ }^{15}$ Tras varios meses intentando cumplir el encargo, que implicó al citado Ridolfi, y pasar por algunas dificultades, Metastasio escribe lo siguiente a Farinelli:

Tengo mejores esperanzas sobre los caballos que la semana pasada, pero hoy no tengo tiempo ni necesidad de hablar sobre ello. ¡Oh, caro gemelo, qué diabólica comisión! Vos reís y yo pierdo la cabeza. ¡Paciencia! El honor de secundar las premuras de los dignísimos señor duque de Medinaceli y el señor marqués de la Ensenada será mi eléboro (Metastasio, 1954, p. 455).

La comisión, en definitiva, involucró a Ensenada y al duque de Medinaceli, que en 1749 había sido nombrado caballerizo mayor. Esto explica que Medinaceli y Ensenada vuelvan a aparecer juntos en la correspondencia de Metastasio el 1 de agosto de 1750. El propio Farinelli se refiere a este encargo en su Descripción, donde explica que los caballos llegaron primero a la casa de campo del duque de Medinaceli, dirigiéndose después al Escorial, no sin antes bromear con que una comisión tan particular fuera encargada a un poeta por medio de un músico:

En el año de 1749 se pensò hacer venir para la Real cavalleriza de S. M. el Rey de España, dos mudas de Cavallos para carroza, y trèn de $S$. M. la Reyna nuestra señora, de la Casta del Principe de Sarzemberg, y de la del Principe de Lichtestein.

Se dio la comision al señor Metastasio, y en respuesta escrivio en estos terminos: Chi Diavolo vi hà posto in testa di dare una simile commissione, cosi delicata, e scabrosa ad un Poeta? [«¿Quién diablos os ha puesto en la cabeza dar una comisión como esta, tan delicada y escabrosa, a un poeta?»]

Se le respondiò: e quando credeva il Poeta che gli fosse data dà un Musico? [«¿YY cuándo creyó el poeta que le sería dada por un músico?»]

En fin dio aviso Metastasio de aver hecho la comision, y dispuso su marcha de Viena à Madrid.

En el año de 1750 llegò felizmente la expedicion a la Piovera Casa de Campo del Sor. Duque de Medinaceli cavallerizo mayor del Rey nuestro señor, y se detubo en ella hasta la vuelta de la Corte del Escorial.

parte delle belle qualità del suo core. In somma voi siete nato per gustar quanto può dar di dolce I'umanità: la vicinanza d'un amico di quel calibro non è l'ultima delizia della vita» (Metastasio, 1954, p. 535).

15 Este encargo y otros asuntos de la correspondencia con Metastasio están tratados genéricamente en Valente (2007). Sobre la extensa correspondencia entre ambos véase también Savage (2005 y 1998) y Heartz (1984). 
Todo el gasto de la principal comision, y expedicion, està en la Contaduria de la Real Cavalleriza.

No se perdio tiempo en dàr las gracias a Metastasio por aver cumplido esta comision, que la desempeñò a toda satisfaccion, y con la misma ocasion se le acompaño una sortija de un Brillante de 20 granos en figura de corazòn de color amarillo (Farinelli, 1992, pp. 185-187).

Esto demuestra que Farinelli era utilizado como enlace con la corte de Viena, ayudando a personajes como Ensenada y Medinaceli. Otra carta importante de Metastasio en este contexto es la dirigida a Anna Francesca Pignatelli el 26 de abril de 1750. Metastasio ha solicitado a la reina de España, a través de Farinelli, una pensión eclesiástica, y le cuenta que acaba de recibir una respuesta del duque de Losada dirigida a Ensenada, que se ocuparía del asunto por mandato de la reina. Esta es la respuesta, transcrita por Metastasio en español: «S. M. me ha mandado decir a V. M. que no obstante no averse concedido ninguna pension desde que por Metastasio se interpuso esta solicitud, procurarà S. M. buscar el modo de que quede la Reyna luego obsequiada con ello» (Metastasio, p. 631; Metastasio, 1784, p. XVI; Metastasio, 1786, pp. 307-8; cf. Metastasio, 1954, pp. 500, 662, 694 y 725). No por casualidad, el poeta cesáreo reconoce en julio de ese año la «ventaja» que él mismo obtiene de la relación del castrato con «este dignísimo señor marqués de la Ensenada», agradeciéndole haberlo «seducido en mi favor» ${ }^{16}$.

Ya hemos visto en la correspondencia de Keene que Farinelli defendió a Ensenada en los meses cercanos a su caída. Según cartas posteriores del mismo embajador, Farinelli mantuvo su confianza hacia Ensenada después de su caída y expulsión a Granada. El 25 de septiembre de 1754, Keene incluso muestra su deseo de enviarlo a Granada junto al padre Francisco de Rávago, confesor de Fernando VI desde 1747 -o, como lo llamó Juan José Ortiz de Amaya, «el delicado director de la delicada consciencia de nuestro gloriosísimo monarca»- ${ }^{17}$ y gran apoyo del ministro, que precisamente "pagaría su lealtad al marqués con la destitución» al año siguiente (Gómez Urdáñez, 2020). La carta de Keene deja claro su interés: «dado que ahora estoy desocupado e inactivo, con gusto llevaría en mis hombros al

16 «La generosa parzialità che secondo le vostre lettere dimostra a mio vantaggio cotesto degnissimo signor marchese Enseñada è un effetto delle vostre appassionate relazioni. Già che lo avete sedotto a mio favore, ora non vi sta bene di disingannarlo. Tirate innanzi, e ditegli sempre di belle cose intorno al trascendente merito mio; e quando volete parlargli di me senza pericolo di esagerar la verità, parlategli della mia venerazione e della mia riconoscenza. Vi disfido su questi soggetti di poter accrescere il vero». Carta del 18 de julio de 1750 (Metastasio, 1954, p. 548).

${ }^{17}$ Reverente representacion, que a el ilustrissimo, y reverendissimo padre Francisco Rabago, confessor de su magestad catholica, hace el doctor Don Juan Joseph Ortiz de Amaya, cavallero jurado del muy ilustre cabildo de la ciudad de Sevilla, BNE VE/451/48, A2. 
confesor a Granada, y después regresaría para hacer lo mismo con el músico para que le cantara» (Keene, 1933, p. 384) ${ }^{18}$.

En el citado prólogo a la obra de Millán, Barbieri dudaba que Farinelli hubiera sido partidario de Ensenada, aduciendo en contra, precisamente, que no se produjera esta caída augurada por Keene. Este argumento ad absurdum sería válido si alguien hubiera supuesto una colaboración del cantante en los planes geopolíticos de Ensenada, algo que resulta incongruente con las acusaciones que nos han llegado. Ensenada fue acusado de romper la neutralidad política de España frente a Inglaterra y Francia, algo de lo que nadie parece haber acusado a Farinelli, ni siquiera Keene. El propio Ensenada, en la citada carta del 15 de junio, donde apela a su amistad de la manera más efusiva, deja claro que Farinelli no está al tanto de sus asuntos y espera no haberle decepcionado:

Vm. no ofenderá su penetración ni su noble modo de pensar recelando que yo le haya sido infiel, pero quiero me oiga que he sido su amigo de corazon, que lo soy, y que en cualquier situacion lo seré hasta morir (Rodríguez Villa, 1878, p. 190).

El único «error» imputable a Farinelli, si es que hubo alguno, habría consistido en confiar en la palabra de Ensenada. Nada impidió, de hecho, que unos meses después de su caída, el marqués redactara otra carta dirigida a Farinelli, donde se defendía de sus acusadores, con la intención de que el cantante se la entregara a la reina. Allí, el marqués se muestra comprensivo por que Farinelli debiera "suspender el juicio sobre mi amistad», repitiéndole que "crea como en Dios que se la mantendré de todo corazon hasta el último aliento de mi vida». En esa carta deja este interesante testimonio sobre la colaboración entre ambos:

hallo que $V m$. debe no repugnar esta comision, pues habiendo sido y siendo garante de mi proceder, es Vm. el principal interesado, y por consecuencia es de su obligacion asegurarse de lo que yo he sido y soy, pues no es razon que Vm. viva engañado creyéndome hombre de bien no siéndolo (Rodríguez Villa, 1878, pp. 209213; la cursiva es mía).

Su perfil político, en definitiva, parece estar más vinculado a su cercanía con los reyes, que le situaba en una posición privilegiada como mediador en todo tipo de asuntos, que a la colaboración directa en asuntos de gobierno. Aparte de la reclutación de artistas y el encargo de materiales operísticos, que requerían acudir a los cauces diplomáticos habituales, sabemos que ciertos personajes de la corte

${ }_{18}$ Que el embajador inglés mantuvo esta opinión años después queda probado en Coxe (1813, p. 195). 
trataron de involucrarle puntualmente en sus manejos ${ }^{19}$, y que recibió peticiones de ascenso de políticos importantes. En una carta del 12 de mayo de 1747, por ejemplo, Bernardo Tanucci asegura que el rey de Nápoles ha intentado que Farinelli "persuada a la Reina de España» para nombrar a un candidato suyo como «embajador católico en Roma». ${ }^{20}$ De igual modo, conocemos su intervención para asegurar la dedicatoria de la Storia della musica del padre Martini a Bárbara de Braganza (Pasquini, 2017) o la citada pensión para Metastasio. Pero obviamente Farinelli no podía influir en un cambio de rumbo político tan drástico como el que pudo hacer Ensenada a través de su red de colaboradores en Europa (Taracha, 2001).

Otra prueba de la cercanía de los reyes con Farinelli la encontramos en Facundo Mogrovejo. Tras su destierro a Burgos, precisamente por colaborar con el marqués, le recuerda a Ricardo Wall que apenas había obtenido favores políticos, salvo «una pequeña pension sobre el obispado de Barcelona», afirmando en su descargo que "fue D. Carlos Brosqui quien me estimuló á solicitarla y protegió para obtenerla» (Rodríguez Villa, 1878, p. 393). Como en el caso de las cartas de Ensenada, se trata de un testimonio único sobre el poder de Farinelli, pero no prueba que fuera determinante en los asuntos por los que se acusó a Ensenada. Que el abate Mogrovejo y Ensenada utilicen a Farinelli para defenderse parece probar, más bien, lo contrario.

Del mismo modo, la involucración de Ensenada en las óperas del Retiro, tal como la describen los libelos de la BNE, es claramente tendenciosa, aunque no podamos negar su contribución general como ministro, ${ }^{21}$ su asistencia a algunos ensayos, su mediación para conseguir libretos e instrumentos (Gómez Urdáñez, p. $94,113 n$ y p. $106,156 n$ ) o publicitar la gestión de Farinelli en las gacetas de Holanda ${ }^{22}$ y su correspondencia con embajadores como el duque de Huéscar, donde

19 Véanse las cartas 649, 803 y 824 en Ozanam y Téllez Alarcia (2010) donde se habla de la conexión de Farinelli con otros políticos. De otras cartas nos ocuparemos a continuación.

20 "Le nostre promozioni, per le quali Appulis iunguntur caprae lupis, vengono da venti diversi. II Re ha fatto Crivelli, Sora, Farina, perché il musico Farinello persuada alla regina di Spagna il far questo guelfo magnate ambasciator cattolico in Roma» (Tanucci, 1980, pp. 243-4). Véase también la carta de Farinelli al conde de Torrepalma el 27 de febrero de 1758 en Archivo Histórico de la Nobleza, baena, C. 395, D. 615, ff. 1-2, donde Farinelli asegura que ha informado a los reyes de sus deseos de conseguir la embajada de Turín (cit. en Domínguez, 2015, pp. 33-34; transcripción en pp. 52-53).

${ }^{21}$ Así, por ejemplo, una defensa contra sus acusadores incluida en el citado Mss/11038, se refiere a la importancia de sus gestiones para realizar diversos gastos acaecidos "en su tiempo", incluyendo «el extraordinario de la Boda de la Ynfanta Duquesa de Saboya: el de las operas, y otros tantos de no tanta consideracion» (f. 255).

${ }^{22}$ Así en su carta a Huéscar el 18 de diciembre de 1747: «Haga Vm poner, sin que nadie lo entienda, en la Gaceta de Holanda un capítulo consecuente al que sobre la pastoral le enviará a Vm Ordeñana como por noticia casual, y pase a otras Gacetas pues esto y mucho más merece Farinello» (Ozanam y Téllez Alarcia, 2010, p. 356). Sin embargo, la intencionalidad de esta acción no es sólo contentar a Farinelli. Como demuestra otra carta de Ordeñana a Huéscar, en la que le 
aparecen algunas menciones a la ópera. En el extenso inventario de su biblioteca del 27 de julio de 1754, ordenado por Wall, sólo encontramos «seis tomos en ocho Obras de Metastasio», así como algunos «libros de Operas» guardados «en lo bajo de los cajones» junto a otros papeles (inventario en Gómez Urdáñez, 1996, p. 268 y p. 270). El propio ministro atribuye las óperas a Farinelli y a los reyes. Así se refiere a Angelica e Medoro, con libreto de Metastasio y música de Giovanni Battista Mele, en la carta que escribe a Huéscar el 13 de diciembre de 1747:

Magnífico teatro ha hecho aquí Farinello. Y para el día 18 hay una ópera con música especial de Mele sin que la Reina lo sepa, pues la quiere sorprender el Rey (Ozanam y Téllez Alarcia, 2010, p. 355).

Poco después, Ensenada relata el éxito de esta ópera a Huéscar, que le traslada su "envidia» y bromea con la pesadez de las óperas de Lully que, en su calidad de embajador de España, se ve obligado a escuchar en París, atribuyendo de nuevo a Farinelli la iniciativa de realizar las óperas:

Harta envidia tengo a $\mathrm{Vm}$ por lo que se divierten. Mal provecho haga a $\mathrm{Vm}$ y diga $\mathrm{Vm}$ a Farinello que si hace más fiestas mientras yo no las pueda ver, que le he de llevar dos Francesas para que le canten una ópera de Lully para que le dé un dolor de estómago. iSe puede ver picardía como hacer cosas tan magníficas sin que yo las vea! Para vengarme de $\mathrm{Vm}$ ando buscando trazas y, mientras me llegan, reciba Vm mi buena voluntad y a Dios (Ozanam y Téllez, 2010, p. 370). ${ }^{23}$

En estas cartas se observa la complicidad de Farinelli con Ensenada, que le traslada estas bromas de Huéscar y hace de mediador para responderle. El 22 de enero de 1748, por ejemplo, leemos en otra carta de Ensenada dirigida a Huéscar: «dice Farinello que con sólo haber oído el nombre de Lully tiene dolor de estómago» (Ozanam y Téllez, 2010, p. 373). En el mismo sentido puede leerse la carta dirigida a Huéscar el 1 de febrero de 1748, donde Ensenada habla de su asistencia a un ensayo de ópera, que podemos identificar con Polifemo, e Galatea de Paolo Rolli, con música de Corselli, Corradini y Mele, realizada al día siguiente para la Fiesta de la Purificación de Nuestra Señora:

solicita informar de otras óperas en las gacetas, esto se hace «para que sepa el Mundo que en razón de teatro y sus funciones excede esta corte a las demás» (Domínguez, 2015, p. 41).

${ }^{23}$ Algo parecido afirma el 16 de febrero de 1748, cuando Huéscar escribe a Ensenada: «Mal provecho hagan a Vms las óperas que ven. No me diga Vm nunca si el teatro está bueno o malo, ni que Farinello tiene buen gusto y disposición, porque además de saberlo yo, no quiero que Vm me añada motivos de envidiar sus diversiones» (p. 384). 
Anoche hubo prueba secreta de ópera que me gustó porque agradó a los Amos, pues en la música hay tantos defectos como perfecciones en el teatro, vestuario, mutaciones, y todo lo demás que dirige Farinello (Ozanam y Téllez, 2010, p. 379).

Más plausible resulta que ambos influyeran (aunque de nuevo en diferentes grados) en la planificación de los paseos acuáticos por el Tajo, que parecen querer superar los paseos de Jorge I en 1717 por el río Támesis con música de Händel, todavía recordados en esta época ${ }^{24}$, o los paseos versallescos de Lully y sus "góndolas venecianas» (Gómez Urdáñez, 1996, p. 107), aunque en realidad tienen sus propios precedentes -muy anteriores- en las fiestas reales españolas, tanto en el Tajo como en otros lugares ${ }^{25}$. Farinelli y Ensenada eran sin duda dos buenos candidatos para aprovechar esta tradición: el primero, por su oficio como organizador de festejos, pero también por su paso por Londres durante tres años, coincidiendo allí con Händel; el segundo, por su interés en reforzar la marina frente a los ingleses, para lo cual realizó todo tipo de esfuerzos, desde la diplomacia y la reclutación de extranjeros hasta el espionaje. Como luego veremos, los paseos por el Tajo podrían estar concebidos para sugerir a los extranjeros de Aranjuez la grandeza naval española ligada al proyecto de Ensenada (Sancho Gaspar, 1998, p. 180).

Pero no hemos de olvidar que los embarcos por el río Tajo se empezaron a realizar precisamente en 1754, cuando la caída de Ensenada era prácticamente inevitable. El marqués embarcó once veces ese año entre el 21 de junio y el 5 de julio, junto a los reyes y el propio Farinelli, en la embarcación denominada La Real, apenas cinco días después de escribir al músico la carta donde le solicitaba su mediación para que la reina aceptase su dimisión. Después de ese año, no volvería a embarcar. En 1755 se hicieron catorce embarcos, seguidos de nueve en 1756 y once en 1757, en todos los cuales estuvo Farinelli junto a los reyes. Que el proyecto se consolidara un mes antes de su caída y que, sin embargo, se mantuviese durante tantos años después, nos obliga a desbordar el plano de la explicación personal.

${ }^{24}$ Un año antes de llegar Farinelli a Inglaterra, por ejemplo, se publicó Händel (1733) , y todavía en 1760, en una curiosa biografía de Händel, «An Account of the Life of George Frederick Handel», encontramos un largo párrafo sobre esta música acuática (Anónimo, 1760, p. 311). Cf. Cappelletto (1995, p. 86).

${ }^{25}$ Álvarez de Quindos y Baena (1804) afirma que «antes del año de 1585, y en el de 1566, estaba en planta la navegación del Rey en el rio Tajo» y, en tiempos de Felipe III, "vino una persona Real embarcada en góndolas desde Lisboa [...] con gran acompañamiento de barcos y músicas, haciendo tránsitos hasta llegar á Aranjuez, donde estaba el Rey, que se divirtió mucho con la agradable vista de tantas embarcaciones adornadas de flámulas y gallardetes, músicas y concurso de gentes» (pp. 384-5). Este tipo de paseos se hicieron también en otros lugares, como el Retiro y la Granja de San Ildefonso. En el Museo de Falúas Reales, como es sabido, aún se conserva una falúa encargada por Carlos II. 
El manuscrito, por otra parte, sólo habla de "ayudar», y además pone más énfasis en las obras del río que en el proyecto mismo, de igual modo que debió encargar la casa de Farinelli en Aranjuez, construida cerca de las casas de Carvajal y el propio Ensenada (Torrione, 1996, pp. 323-333). También resulta obvio, como en el caso de las óperas, que el peso de la organización recayó sobre Farinelli, como por otra parte es razonable teniendo en cuenta las variadas ocupaciones de Ensenada, y como demuestra también el citado manuscrito del castrato sobre las óperas del Retiro y las fiestas de Aranjuez, a todo lo cual podríamos sumar su propia presencia física en las embarcaciones, que también formó parte del espectáculo.

\section{ENSENADA Y FARINELLI: LA MIRADA ESPECULAR DE JACOPO AMIGONI}

Lo esencial, en todo caso, es la sintonía entre los proyectos de Farinelli y Ensenada. Los retratos de ambos personajes realizados por el pintor y amigo de Farinelli, el italiano Jacopo Amigoni, son quizá la mayor prueba que hemos conservado al respecto. La similitud entre ambos retratos ha pasado inadvertida, pero tienen casi la forma de un espejo (véase la Tabla 2). ${ }^{26}$ Ambos personajes aparecen en un plano de tres cuartos con sus atuendos cortesanos y las insignias de su orden: el Toisón de Oro en el caso de Ensenada y la orden de Calatrava en el caso de Farinelli, que reflejan su elevación de rango en la corte de Fernando VI hacia 1750. Juntos parecen representar las dos caras de la política monárquica: lo estatal y lo palaciego, las armas y las letras, la razón de Estado y el entretenimiento, la civilización y la naturaleza. Donde Ensenada tiene su espada, Farinelli tiene una partitura; si el ministro se sitúa delante de un edificio con columnas dóricas, sosteniendo un bastón, el músico lo hace junto a los árboles de Aranjuez, acompañado por un perro que simboliza su fidelidad; donde el primero deja entrever los barcos que destacan su empeño por consolidar una reforma naval, el segundo posa junto a las embarcaciones del río, como si fuera una especie de recreación en miniatura del poderío de la flota española. Las empresas de Farinelli y Ensenada aparecen así unidas en estos retratos, que reflejan una visión complementaria dentro de la corte.

${ }^{26}$ Para una imagen general de los retratos de Farinelli véase Heartz (1990, pp. 430-433, 435, 437-441 y 443). 


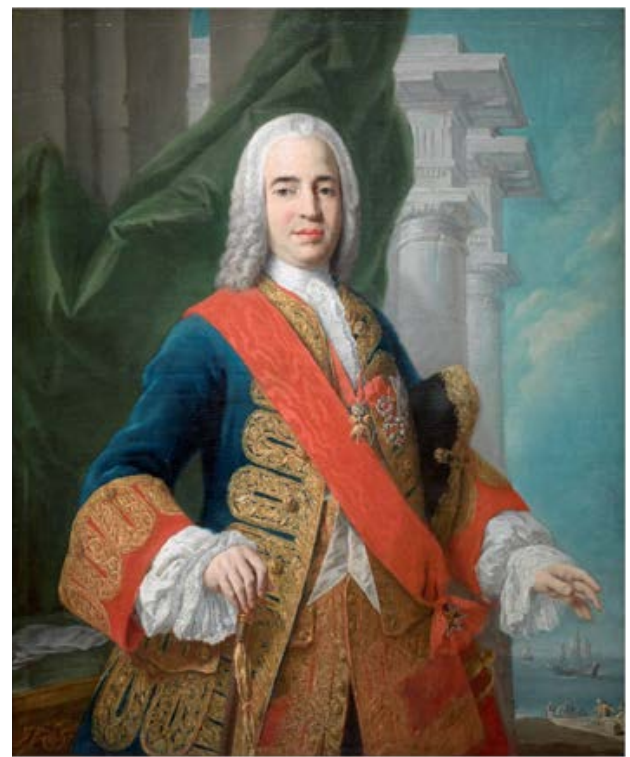

Figura 1. Retrato del marqués de la Ensenada (c. 1750), óleo sobre lienzo de Jacopo Amigoni. Museo del Prado, P002939.

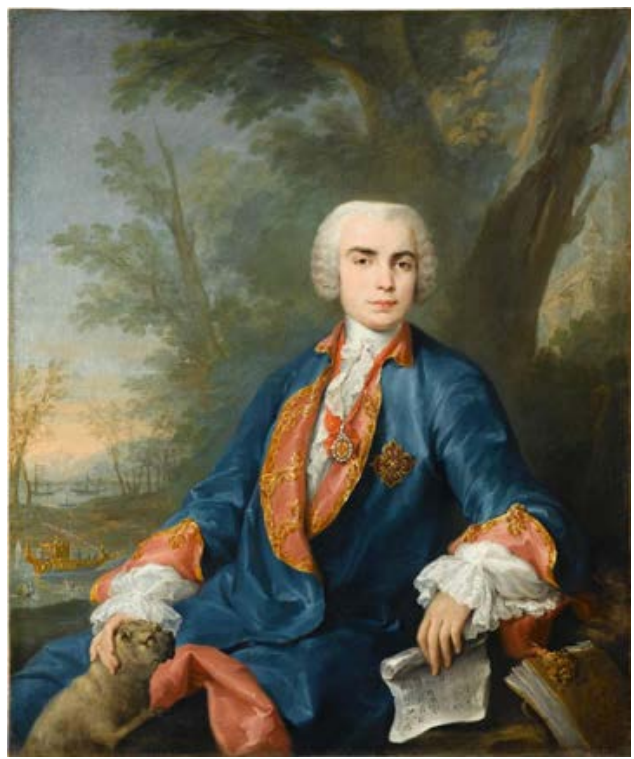

Figura 2. Retrato de Carlo Broschi Farinelli (c. 1750) de Jacopo Amigoni. Staatsgalerie Stuttgart, 3163.

Tabla 2. Comparación entre los retratos del marqués de la Ensenada y Carlo Broschi Farinelli realizados por Jacopo Amigoni

Estos cuadros casi cobran vida cuando recordamos que, al menos durante once días entre junio y julio de 1754 , los invitados de Aranjuez, a los que las gacetas siempre se refieren de modo genérico como "prelados», "grandes», "embajadores», «ministros extranjeros» $y$ "otras personas distinguidas de ambos sexos», pudieron verlos juntos en la embarcación, acompañando a Fernando VI y Bárbara de Braganza. Entre los más de cincuenta pasajeros de La Real, donde destacaban otros príncipes, duques y marqueses, junto a otros personajes, todos ellos acompañados por ocho músicos y veinticuatro marineros, estaba también el duque de Huéscar, nombrado mayordomo mayor tras su vuelta de París. Que Huéscar contribuyera a la caída de su «amigo» Ensenada en 1754, produciendo la victoria de los intereses ingleses junto a Keene y Wall, demuestra de un modo casi visual que las embarcaciones del Tajo desbordaban el plano de la oposición entre Inglaterra y España. Frente a la ausencia de Ensenada, volveremos a ver a Huéscar en los embarcos de 1755 y 1756, en este último caso como duque de Alba. En cierto modo, Farinelli debía mantener, como cualquier ministro, el sistema de neutralidad de Fernando VI, lo que sin duda le obligaba a ser «amigo» de Keene ${ }^{27}$.

${ }^{27}$ En este punto, puede ser interesante destacar que Keene aparece en la Descripción de Farinelli por haber conseguido para España al cantante Antonio Catena (Broschi Farinelli, 1992, f. 340). 
En definitiva, como ocurría en el ámbito de la ópera, era más importante la invocación de un poder genérico, prudente y de largo alcance que la política inmediata, ya sirviera como alegoría de la reforma naval o como competencia contra los ingleses. Los barcos no eran más importantes que la dignidad de los personajes, los trajes, las luces, la caza, el canto y el entorno palaciego, elevados a través de un espectáculo único en Europa. A la embarcación conocida como La Real seguía la fragata San Fernando y Santa Bárbara, donde iban las correspondientes princesas, duquesas, marquesas y condesas, acompañadas por quince músicos; a continuación, navegaban otras tantas camaristas y dueñas en el jabeque Orfeo, y los mayordomos y oficiales de Corps en el jabeque Tajo. Todo ello formaba parte del espectáculo, enriquecido por una extraordinaria iluminación compuesta por miles de luces, mientras los reyes tocaban el clave y cantaban junto a Farinelli o cazaban desde la embarcación a la vista del selecto público allí congregado. Reducir esto al interés de un grupo terapéutico por mantener entretenidos a los reyes resulta, como mínimo, limitado.

\section{NUEVOS LIBELOS Y LA CORRESPONDENCIA CON BERNARDO TANUCCI}

Teniendo encuenta lo anterior, resulta lícito preguntarse por qué la amistad con Farinelli ocupa tanto espacio en estos manuscritos destinados a difamar al marqués, un político que se ocupaba de tantos y tan diversos ministerios, desde la Hacienda y la Marina hasta la Guerra e Indias, que había tejido una extensa red de contactos en España y en las cortes más importantes de Europa, y sobre el cual pesaba un número tan elevado de $\operatorname{cargos}^{28}$. Uno de los pasquines citados por Rodríguez Villa nos ofrece una pista sobre su posible intención. Tras mencionar la caída de Ensenada y

28 Sobre estos cargos existen numerosos manuscritos. Véase «Cargos que se hicieron al Excelentísimo Marqués de la Ensenada y satisfación a ello», BNE Mss/18576/14/3, Mss/ 12980/10; Mss/10911, ff. 177-212; «Cargos hechos al Marques de la Ensenada de que resultó su separacion del ministerio, segun asegura Persona muy fidedigna à que se satisface asi como se hara à qualquiera otros que le hayan formado contra la conducta de aquel Ministro», Mss/1962, ff. 2-52; "Cargos hechos al Marqués de la Ensenada, y respuestas a los mismos, de que resultó su separación del Ministerio y de la Corte, reinando Fernando VI», BNE Mss/5710 y "Cargos que se hicieron al Marques de la Ensenada para separarle del Ministerio, y respuesta a ellos de que se conoce fue impostura quanto de el dixeron, y viles, medios de que se balieron sus emulos para derribarle» en el citado BNE Mss/11038, ff. 228-271; uno de esos cargos era que gastaba "gruesas Cantidades en embiar gentes à Estudiar à Payses extrangeros, y en otras cosas inutiles al Estado" (f. 251); otro, que "todo se hacia en su nombre como si el Rey no fuese el Dueño soverano, y dispensador de todas las gracias, abusando de las facultades que le tenia concedidas" y que "gastava un lujo impropio de un vasallo, y con humor de soberano" (f. 257), así como acusaciones a sus hombres de confianza, especialmente a Agustín de Ordeñana, que «tambien usaban mal de su confianza» (f. 262). 
de Ordeñana, augura la propia caída del castrato en unos términos que recuerdan a la carta anteriormente citada de Keene:

\author{
Desterraron a Ordeñana, \\ Y asimismo a Don Cenon; \\ Mañana saldrá el Capon \\ Cantando la Tirirana (Rodríguez Villa, 1878, p. 401).
}

Un caso parecido se encuentra en el manuscrito Ms/10912 de la Biblioteca Nacional, que contiene unas décimas contra el marqués de la Ensenada, en este caso alusivas al padre Rávago. En ellas vuelve a aparecer su conexión con «el capón», remarcando la importancia de ambos para Ensenada ${ }^{29}$ :

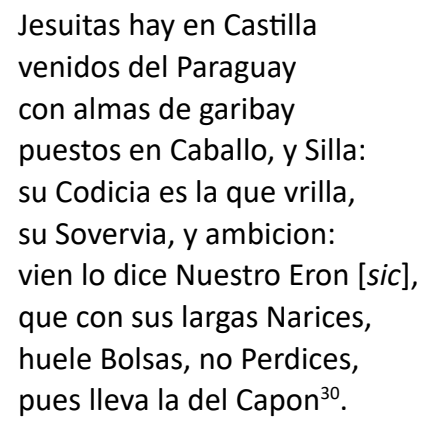

Los manuscritos incluyen así un ataque doble que apela a ambos personajes, aprovechando las analogías antedichas: la mención a la «tramoya», al fingimiento de la corte, a las continuas dádivas, al espionaje y a los devaneos cortesanos, encuentran en la imagen del «capón» un símbolo perfecto. A ello contribuye la extensa tradición de textos denigratorios dirigidos contra los «capones» o «eunucos» ${ }^{31}$.

29 Gómez Urdáñez (2017) considera que Farinelli y el padre Rávago eran «las dos piezas claves del mundo cortesano" y que ambos convencieron a la reina Bárbara de Braganza para nombrar a Ensenada su secretario (p. 71). Sobre el perfil político del confesor jesuita véase Guasti (2013), pp. 1199-1223. Este último cita una carta de Wall a Portocarrero de mayo de 1756 donde afirma que «el padre Rávago, los colegiales, los ensenadistas se han unido y estos tres cuerpos hacen y dicen lo que quieren y pueden impunemente» (p. 1209).

30 BNE, Mss/10912, f. 107.

${ }^{31}$ Withof (1756) apareció reseñado en Mariano Nipho (1763) con la mención a los «Eunucos, ò Capones» como "hombres neutros», relatando las "variaciones que causa en la configuracion de la persona» la castración («la fatal operación»). El texto los tacha de «maliciosos» y les atribuye características femeninas, asegurando que «una Muger puede conocer á un Capón con solo el olfato» (p. 100). Estas palabras recuerdan a la invectiva del médico Bernardo Robredo (1636), para quien los capones eran «un género de gente imperfecta, mutilada y truncada», además de 
Los manuscritos lamentan que Ensenada haya mostrado más aprecio por los músicos que por los héroes de guerra, indignándose por que las cantantes italianas, contratadas para las óperas del Retiro y las serenatas de Aranjuez, fueran recibidas en Madrid como generales que vuelven del campo de batalla tras una victoria, no sin antes tomarse todo tipo de molestias para llevarlas a la capital desde el puerto de Barcelona, para después alojarlas a costa del rey.

La llegada de Carlos III, simbolizada por la famosa chanza que Joseph Baretti atribuyó espuriamente al nuevo rey («los capones sólo me gustan sobre la mesa»), expresa esa incomodidad ante el mundo operístico, un ejemplo más de la rumorología que pudo contribuir a que el nuevo rey diera ese paso. Aunque Carlos III nunca pronunciara esa frase, que sólo se le atribuye una década después, y aunque sabemos que pagó un sueldo vitalicio a Farinelli del cual vivió en Bolonia durante dos décadas, el desinterés por los proyectos operísticos muestra un cambio evidente en la política del nuevo rey.

Por supuesto, hemos de tener en cuenta otras múltiples causas, no siendo la menos importante que Farinelli, tras haber servido durante tantos años a Fernando VI, ya no podía ser mirado con buenos ojos por Isabel de Farnesio, que había acumulado tanto rencor contra la nueva pareja real desde la muerte de Felipe V. También hemos de tener en cuenta que Carlos III no había tenido ninguna "amistad» con el cantante antes de ser rey, como sí la habían tenido Fernando VI y Bárbara de Braganza, garantizando su continuidad tras la muerte de Felipe $\mathrm{V}$.

Por otra parte, en la correspondencia de Bernardo Tanucci, encargado de la política exterior de Nápoles en los últimos años del reinado de Fernando VI, se observa cierta incomodidad con la figura del cantante. El 19 de julio de 1757, en el contexto del asedio de Ceuta por parte de Marruecos, Tanucci escribe al príncipe de Aci preocupado por la propagación de ciertos rumores, según los cuales el asedio habría sido provocado por los ingleses. Tanucci atribuye estos rumores precisamente a Farinelli, a quien se cree favorable a los intereses de Francia y Austria frente a Inglaterra. A esto acompaña un juicio muy negativo sobre el papel de los favoritos de los reyes, categoría en la que se incluye a Farinelli, pues influyen en la política sin tener una responsabilidad de gobierno, inmiscuyéndose en asuntos de gravedad sin verdadero conocimiento e influyendo en la voluntad del rey contra sus ministros. Nótese que Farinelli habría extendido esos rumores precisamente a través de los embajadores de Francia y Austria:

ser hombres "odiosos, viles, bajos, estériles», pero también «afeminados, lascivos, impúdicos», incluso "traidores, alevosos, invidos, codiciosos, avarientos y glotones», entre otros calificativos que ni sus peores enemigos podrían atribuir a Farinelli, como "hombres menospreciados» (Medina, 2011, p. 79). Aunque no hemos de olvidar, como destaca Medina, que en general Farinelli «representa el modelo del eunuco bueno» (p. 156). 
Así que Farinello está cerca de Rosemberg, a quien se debe haberle dicho al Rey que los ingleses habían incitado a Marruecos para sitiar Ceuta. Lo que Farinello hace con Rosemberg, lo hace con Aubeterre y con otros, y está bien. Esto sucede cuando el favor y el interior de las cortes se abre a este género de personas. Parece que Farinello es más francés que inglés y también parece estar cerca de ser austríaco, una secta que quizás adoptó como afrancesado. No hay nada que desanime más a los honorables ministros de un Soberano que estas figuras interiores, que no estando obligadas a responder por la conducta del gobierno, hablan del gobierno clandestinamente y de los negocios. Mueven al Soberano, al cual no puede discutir el ministro. No lo pueden reconvenir; al contrario, a veces sucede que, obligado por el curso del tiempo el principio del negocio, el propio ministro debe ser reconvenido. Si el ministro es de sangre fría, se adapta a no hablar, a no proponer, a no oponerse; pero si es un poco caliente en sangre y celo, se aflige, se atormenta, se duele, y finalmente sucumbe al odio de la Corte y a la irritación del Soberano, y desea su descanso... ${ }^{32}$.

En otra carta al marqués de Maio, escrita el 26 de julio de 1757, Tanucci insiste en que «el conde de Rosemberg, ministro de España de esta corte [de Viena], está bien informado y es amigo de Farinelli». ${ }^{33}$ El asunto reaparece en varias cartas de Tanucci, que insisten en la conexión de Farinelli con Ensenada. El 30 de agosto, escribe al marqués de Maio que nadie en Nápoles ha creído los rumores, por provenir «del partido del destronado Ensenada». ${ }^{34}$ Que con ello se refiere a Farinelli queda claro en otra carta del 6 de septiembre de 1757, escrita al príncipe Albertini, donde le hace conocer su interés por «deshacer en la Corte de España la voz de la facción de

32 «Dunque Farinello è stretto con Rosembergh, a cui palesa I'aver egli solo fatto saper al Re che gl'Inglesi avevano stimolato Marocco e far l'assedio di Ceuta. Quel che Farinello fa con Rosembergh, farà con Aubeterre en con altri, e va bene. Questo avviene quando il favore e l'interno delle Corti si apre a questo genere di persone. Pare che Farinello sia più francese che inglese e pare anche vicino ad essere austriaco, setta che forse egli ha adottato per francesismo. Non è cosa che più disanimi gli onorati ministri d'un Sovrano che queste figure interiori, le quali non essendo obbligate a rispondere della condotta del governo, di governo clandestinamente parlano e di affari. Muovono il Sovrano del quale non può poi il ministro far querela. Non lo può riconvenire; anzi talora avviene che obliato pel corso del tempo il principio dell'affare, debe il ministro stesso esserne riconvenuto. Se il ministro è di sangue freddo, si adatta a non parlare, a non proporre, a non si opporre; ma se è di un sangue e di un zelo un poco caldo, si afflige, si tormenta, si duole e finalmente o soccombe all'odio della Corte e irritazione del Sovrano e desidera il suo riposo» (Tanucci, 1985, p. 157).

33 «il conte di Rosenbergh ministro in Spagna di cotesta Corte è ben informato ed è amico di Farinello» (Tanucci, 1985, p. 159).

34 «Non dubiti del vento inglese nella Corte di Spagna. Chi ha ivi predicato che la guerra de' Mori era una suggestione inglese non è stato creduto, perché del partito del detronato Ensenada; questo stesso lo ha fatto credere a Rosembergh, che lo avrà scritto costà» (Tanucci, 1985, p. 260). 
Ensenada y de Farinelli». ${ }^{35}$ De algún modo, en Nápoles todavía se percibe a Farinelli como un ensenadista, pese a la caída del marqués tres años antes.

Sin embargo, esto no significa necesariamente que Farinelli fuera mal visto por parte del Rey de Nápoles. En otra carta del 30 de agosto, también dirigida a Aci, Tanucci asegura que el rey siente cierta admiración por el músico, pese a que apenas habían "cultivado» una relación con él, imaginando el gran valor que debía tener para la corte, precisamente, por haber seguido gozando del favor de los reyes tras «la desgracia»:

Le doy las gracias a Su Excelencia por la pintura exacta que me hace Farinelli. Nosotros realmente lo hemos cultivado poco. Pero Su Excelencia conoce al Rey. No es capaz de ninguna cobardía ni de ninguna acción que se le parezca. Tampoco significa que otros grandes como nosotros se adapten algún momento y se relajen y que Dios mismo quiera que todos, aunque pequeños, hagan mucho bien y mucho mal a veces, nos enseñen la estima universal y la indulgencia; pero él se mantiene firme en su heroísmo. Lo que más le gustó de Farinello fue la amistad profesada y continuada y transmitida a las MM. Católicas incluso después de la desgracia ${ }^{36}$.

Tanucci nos sirve así para aclarar la situación de Farinelli en la corte. Al contrario de los ministros, su función no está vinculada al gobierno, sino a la privanza de los reyes. Sin esa conexión de amistad, el papel de Farinelli pendía de un hilo. El 9 de diciembre de 1760, cuando Carlos III ha permitido a Ensenada volver a Madrid, Tanucci escribe a Aci conectando, una vez más, a los dos personajes. Significativamente, Tanucci se pregunta si Farinelli querrá situarse en la corte de Nápoles: «Sobre Ensenada no me encuentro, sé que el Padrón lo ha estimado inocente. Aquí

35 «Spero che mi sarà riuscito disfare nella Corte di Spagna la voce della fazione di Ensenada e di Farinello di essere gl'Inglesi stati incitatori della impresa tentata contro Ceuta da Mori» (p. 279). Esto explica una carta anterior, enviada al marqués de Maio el 30 de agosto del mismo año, donde asegura que "chi ha ivi predicato che la guerra de' Mori era una suggestione inglese non è stato creduto, perché del partito del detronato Ensenada; questo stesso lo ha fatto credere a Rosembergh, che lo avrà scritto costà» (Tanucci, 1985, p. 260). En otras cartas, como veremos, queda claro que quien habla con Rosemberg es Farinelli.

${ }^{36}$ «Rendo a Vostra Eccelenza tutte le grazie per l'esatta pittura che mi fa di Farinello. Noi veramente lo abbiam poco coltivato. Ma Vostra Eccelenza conosce il Re. Egli non è capace d'alcuna viltà o di alcuna azione che la somigli. Né vale a dire che altri grandi quanto noi si adattano qualche momento e si rilasciano e che Dio stesso vuole che ognuno benché piccolo possa talora far molto bene e molto male, per insegnarci una stima e un'indulgenza universale; ma egli si tien fermo sul suo eroismo. Il più che gli sia piacuto di Farinello e stata l'amicizia professata e continuata e detta alle MM. Cattoliche anche dopo la disgrazia» (Tanucci, 1985, p. 264). 
tenemos a Farinelli, no sé si para situarse ${ }^{37}$, y el 20 de enero de 1761 le asegura que «Farinelli ha sido bien visto por todos aquí» ${ }^{38}$.

Todo lo anterior hace aún más interesante que Farinelli y Ensenada tuvieran destinos casi opuestos. Tal como Fernando VI prescindió de Ensenada y mantuvo a Farinelli, Carlos III recuperaría a Ensenada y prescindiría de Farinelli, pero las «caídas» de Farinelli y Ensenada reflejan un hecho análogo, marcado por la construcción de una imagen más o menos legendaria. Significativamente no tenemos constancia de que ambos personajes se comunicaran tras la caída de Ensenada. Incluso tras la muerte de Fernando VI, aunque ambos personajes vivieron durante casi tres décadas más y murieron casi al mismo tiempo, rozando los ochenta años (Ensenada falleció en 1781 y Farinelli en 1782), no parece que volvieran a escribirse.

\section{MELANCOLÍA Y DOMINACIÓN: UNA IMAGEN MITOLÓGICA}

La existencia y cirulación de esta rumurología, junto a los libelos contra Ensenada, se unieron pronto en la literatura a otros mitos sobre el cantante. A través de Keene y Sacchi, la «amistad» entre Ensenada y Farinelli se hizo ampliamente conocida en el siglo XVIII ${ }^{39}$, llegando a principios del siglo XIX a obras como la Universal Biography (1810) de John Lemprière, que incluye una entrada sobre el marqués donde se destaca la relación entre ambos siguiendo la anécdota de Sacchi:

Fue íntimo de Farinelli, quien, como él, había ascendido desde la oscuridad; y cuando fue despedido de su oficio, por las intrigas del duque de Huéscar, su amigo

37 TANUCCI, Bearnardo. Epistolario. ed. de M. G. Maiorini. Vol. IX. Roma: Storia e Letteratura, 1985: "Su questo Ensenada io non mi ritrovo, so che il Padrone lo ha stimato innocente. Qui abbiamo Farinello, non so se per situarvisi» (Tanucci, 1985b, p. 190).

38 «Farinello è stato qui ben visto da tutti, e più da $\mathrm{S}$. Nicandro per gratitudine, per la quale anche vede bene la Castropignano» (Tanucci, 1985b, p. 308). También el 16 de diciembre de 1760 le había escrito a Wall: "Abbiamo qui Farinello, che esige moltissime cortesie da questa nobiltà. Non so se avrà avuta colla Castropignano qualche conversazione. Tutto il mondo si è interessato per lui in un incontro che ebbe colla dogana al suo arrivo, la quale pretese di esser gli incorso nella confiscazione del suo equipaggio per mancanza di rivelazione» (p. 200). Sobre su conexión con el príncipe de San Nicandro, Domenico Cattaneo, también es interesante la carta escrita a Aci el 12 de octubre de 1756: "Farinello carteggia qui col principe di S. Nicandro, aio dei principi; certamente i nostri Padroni lo sanno, e lasciano essere. Io non so se sappiano tutto quello che in quel carteggio si tratta. Tempo fa seppi che vi si trattava il viceregnato di Sicilia per lo stesso S. Nicandro. Non so se altri carteggino collo stesso Farinello; ma mi varrò della scorta, che Vostra Eccelenza mi addita» (Tanucci, 1984, p. 224). Véase también Tanucci (1990, pp. 316, 419 y 429 ; y 1995, p. 208).

\footnotetext{
39 E. g., Anónimo (1782), p. xvii.
} 
tuvo la ceguera de reflexionar sobre la severidad de la medida en presencia de la reina (Lemprière, 1810, p. 474).

Un conocimiento más preciso se extendió a través de las Memoirs of the Kings of Spain (1813) del historiador William Coxe, donde aparece la citada carta de Keene de mayo de 1754. Las conclusiones de Coxe, quien consideraba que Farinelli siguió ayudando a Ensenada contra sus detractores, y en concreto contra Huéscar, gozaron de cierta influencia, como se puede comprobar en varias reseñas contemporáneas de su obra. ${ }^{40}$ La carta también aparece traducida al español en la edición de la obra realizada por el escritor Jacinto de Salas y Quiroga (Coxe, 1846, p. 395). En España, un ejemplo claro de esta influencia aparece en la Historia de España desde los tiempos más remotos hasta el año 1840 (1845):

Quizá mas que a su política debió Ensenada la conservación del mando á la amistad que habia contraido con el célebre cantor Farinelli, que representó tan importante papel en la corte de Fernando y Bárbara, de modo que llegó á ser un personaje histórico (Lavelee, 1845, p. 216).

Un caso más cercano a la mitología se encuentra en la Biografia degli artisti (1840) de Filippo de Boni. En la entrada dedicada a Farinelli, se recoge que «influía en los asuntos políticos» y que "tenía frecuentes conferencias con el ministro de la Ensenada», hasta el punto de haber trabajado para "los ministros de varias cortes interesadas en romper el pacto de familia que Francia proponía al rey católico». Ante esta situación, Farinelli habría sido acusado por la corte, situación de la que se habría librado cantando, en una evidente alusión al mito de la melancolía de Felipe V:

Los envidiosos lo acusaron a la reina; y por ello se introdujo secretamente en una habitación contigua a la de la reina; allí, acompañándose de la cítara, cantó el dolor que sentía por la injusta furia de su soberana. Ella, enternecida, lo llamó, aclarando su inocencia; sólo por su mediación consintió la reina perdonar a los acusadores (Boni, 1840, p. 344).

El primer literato que otorgó una verdadera importancia a esta amistad fue José Somoza y Muñoz, en su «novela histórica y racional» titulada El capón, donde

${ }^{40}$ La obra de Coxe se reseñó ese mismo año en The Critical Review (1813, p. 259), recogiendo la conexión entre Ensenada y Farinelli, que también fue tenida en cuenta en la reseña de su obra en Allgemeine Literatur-Zeitung von Jahre 1816 (1816, p. 282). Igualmente, apareció en Wraxall (1815), quien recoge la opinión de que Farinelli «compartió el poder político de Estado con Ensenada» (p. 73). 
Farinelli acaba sacando de la cárcel al propio Ensenada, dirigiéndole las siguientes palabras:

Amigo, marcho a Italia con el gusto de haber salvado el honor y la vida a un hombre grande, que no ha tenido otro error que el de pensar ser capaz de hacer el bien en esta Monarquía. Al fin, para vuestra gloria, ahí quedarán los libros del Catastro, cual trozos del camino de la plata que atestiguan la grandeza de las empresas romanas (Rodríguez Gutiérrez, 2008, p. 269).

También es interesante el breve cuento «Fernando VI y Farinelli», firmado por el conde de Farraquer, José Muñoz Maldonado, incluido en el apartado «España Caballeresca» del sexto volumen del Museo de las Familias (1848), donde la intervención de Farinelli causa un cambio drástico en el estado de Fernando VI, que decide cambiar a sus ministros y contratar entre ellos a Ensenada, así como otorgar más importancia a las artes y las ciencias en detrimento de instituciones como la Inquisición (Farraquer, 1848, pp. 127-135), obra que inspiró la zarzuela Farinelli de Antonio Afan de Ribera, como él mismo confiesa en su edición del libreto (1855, p. 94).

El signo negativo de la amistad de ambos personajes volverá de la mano de Vernon Lee, que además de sus cuentos y novelas escribió un curioso ensayo titulado Studies of the Eighteenth Century in Italy (1880; 2a ed. 1887). En el capítulo dedicado a Metastasio, relata la relación entre Farinelli, Ensenada y la reina en términos claramente novelescos, añadiendo a ellos su amistad con el «poeta ateo» Tommaso Crudeli:

Ferviente católico, profundamente persuadido de la gracia de la Virgen y los santos, aunque corriendo audazmente hacia el peligro de la condenación por su amistad con el Anticristo en la persona del poeta ateo Crudeli, Farinelli siempre estaba dispuesto a añadir a lo celeste objetos devocionales más terrestres, hacer una Virgen de la amable y malvada Reina de España, y un santo, un apóstol, del filantrópico, pero sin escrúpulos, ministro Ensenada.

En contraposición a Metastasio, continúa Lee, Farinelli «estaba agitado por problemas con los cuales su amigo nunca soñó»:

El combate entre realidad y ficción, entre el embaucador y embaucado; la larga y amarga lucha por mantener a Ensenada en el poder, pese a su insolente ingratitud y su impopularidad, y al mismo tiempo servir a la Reina, enemiga mortal de Ensenada; la lucha por conciliar los planes que para él parecían opuestos, pero igualmente generosos, que eran en realidad igualmente malvados y falsos. Ensenada era un santo, y debía mantenerse en el trabajo; la Reina era una santa y había que ayudarla. Ensenada finge que en realidad se opone a una peligrosa alianza con Francia, que acepta el orden del Saint Esprit y el dinero francés sólo para ganar tiempo mientras maduran las relaciones con Inglaterra. Mientras tanto, está conspirando con Choiseul; todo en 


\begin{abstract}
España sospechan menos Farinelli, se le muestran las pruebas y se niega a creer en la traición de Ensenada. Ensenada, viendo su caso no tiene esperanza, meramente se ríe de su incredulidad e insulta su buena fe. Se detiene al ministro y se le condena; la Reina está sedienta de venganza. Farinelli, traicionado, ridiculizado, se apresura ante el rey, ruega, implora, amenaza. Ensenada es despedido al mero destierro de la corte, pese a la Reina, que le imaginaba vagabundo, prisionero o, mejor, muerto. En medio del esplendor y el poder exterior, el pobre gemelo de Metastasio no era más que un lamentable ingenuo, arrastrado de aquí para allá por una estúpida generosidad, sin poder real y sin demasiada felicidad real (Lee, 1887, pp. 212-213).
\end{abstract}

Este último ejemplo demuestra la facilidad con que los mitos pueden pasar de un signo negativo o positivo a su contrario. La historiografía, como hemos visto, no ha sido ajena a esta mitología. Hechos tan complejos como la contratación de Farinelli, la llegada de la ópera metastasiana a la corte española o la constitución del escuadrón del Tajo, se han podido explicar en ocasiones acudiendo a un simple libelo como el que presentamos aquí, remitiendo en el fondo al tópico de la melancolía que configura el mito de entrada de Farinelli en la corte de Felipe V. Esperamos que este artículo sirva para frenar en lo posible este tipo de explicaciones e incentivar nuevos estudios, sin olvidar que el propio contexto de las cortes europeas del siglo XVIII favorece la aparición de todo tipo de rumores y noticias falsas, de modo que no siempre podremos distinguir mito y realidad.

\title{
9. FUENTES (NO EDITADAS)
}

Anónimo (1754). Le Courrier, n.o LXXXVI, du Vendredi 25 Octobre, p. 345.

Anónimo (1782). Les fastes de Louis $X V$, de ses ministres, maîtresses, généraux, et notables personnages de son regne, l, Ville-Franche.

Anónimo (1813). The Critical Review, vol. IV. London: J. Mawman, p. 259.

Anónimo (1816). Allgemeine Literatur-Zeitung von Jahre 1816. Halle und Leipzig, p. 282.

Anónimo. (1760). An Account of the Life of George Frederick Handel. The Gentleman's and London Magazine. Dublin: John Exshaw, p. 311.

Archives Nationales, Affaires étrangères (Paris), AE/B/I/786, ff. 351-352v y ff. 289292v.

Archivo Histórico de la Nobleza, BAENA, C. 395, D. 614. 
Biblioteca Nacional de España [BNE], Mss/1962, ff. 2-52.

BNE Mss/ 12980/10.

BNE Mss/10911.

BNE Mss/11038, ff. 228-271.

BNE Mss/18576/14/3.

BNE Mss/5710.

BNE, Mss/10912, f. 107.

BNE, Mss/11038, f. 287.

Ortiz de Amaya, J. J. Reverente representacion, que a el ilustrissimo, y reverendissimo padre Francisco Rabago, confessor de su magestad catholica, hace el doctor Don Juan Joseph Ortiz de Amaya, cavallero jurado del muy ilustre cabildo de la ciudad de Sevilla, BNE VE/451/48, A2.

\section{REFERENCIAS BIBLIOGRÁFICAS}

Álvarez de Quindos y Baena, J. A. (1804). Descripción histórica del Real Bosque y Casa de Aranjuez. Madrid: Imprenta Real.

Boni, F. (1840). Biografia degli artisti. Venezia: Co' Tipi del Gondoliere.

Broschi Farinelli, C. (1992). Fiestas reales, ed. facsímil del Consorcio para la Organización de Madrid como Capital Europea de la Cultura. Madrid: Turner.

Broschi Farinelli, C. (2000). La solitudine amica. Lettere al conte Sicinio Pepoli, ed. de Carlo Vitali. Palermo: Sallerio.

Cappelletto, S. (1995). La voce perduta: vita di Farinelli, evirato cantore. Torino: EDT.

Carmena y Millán, L. (1878). Crónica de la ópera italiana en Madrid desde el año 1738 hasta nuestros días. Madrid: Manuel Minuesa. 
Coxe, W. (1846). España bajo el reinado de la casa de Borbón. Vol. III. Madrid: P. Mellado.

Coxe, W. (1813). Memoirs of the Kings of Spain. Vol. III. London: Longman et al.

Domínguez, J. M. (2015). 'Todos los extranjeros admiraron la fiesta': Farinelli, la música y la red política del marqués de la Ensenada. Berceo (169), pp. 11-53.

Farraquer, C. (1848). Fernando VI y Farinelli. En VVAA. Museo de las Familias. (Vol. VI, pp. 127-35). Madrid: Establecimiento Tipográfico de Mellado.

Gómez Urdáñez, J. L. (2002). Carvajal-Ensenada: un binomio político. En J. M. Delgado Barrado y J. L. Gómez Urdáñez, Ministros de Fernando VI Córdoba: Servicio de Publicaciones de la Universidad de Córdoba.

Gómez Urdáñez, J. L. (1999). El duque de Duras y el fin del ministerio de Ensenada (1752-1754). Hispania, LIX/1(201), p. 239.

Gómez Urdáñez, J. L. (2020). "Zenón de Somodevilla y Bengoechea», Diccionario Biográfico (Real Academia de Historia). Disponible online: http://dbe.rah.es/ biografias/6698/zenon-de-somodevilla-y-bengoechea. Última consulta: 1 de abril de 2020.

Gómez Urdáñez, J. L. (2017). El marqués de la Ensenada. El secretario de todo. España: Punto de Vista.

Gómez Urdáñez, J. L. (1996). El proyecto reformista de Ensenada. Lleida: Milennio.

González Caizán, C. (2004). La red política del marqués de la Ensenada. Madrid: Fundación Jorge Juan.

Guasti, N. (2013). El papel político del padre Rávago en la corte de Fernando VI. En C. Martínez Millán, C. Camarero Bullón y M. Luzzi Traficante, M. (coords.). La Corte de los Borbones: Crisis del modelo cortesano. Vol. II (pp. 1199-1223). Madrid: Polifemo.

Händel, G. F. (1733). The Celebrated Water Musick: In Seven Parts. London: I. Walsh.

Heartz, D. (1984). Farinelli and Metastasio: Rival Twins of Public Favour. Early Music, 12(3), pp. 358-366. https://doi.org/10.1093/earlyj/12.3.358. 
Heartz, D. (1990). Farinelli Revisited. Early Music, 18(3), pp. 430-433, 435, 437-441 y 443. https://doi.org/10.1093/earlyj/XVIII.3.430.

Keene, B. (1933). The Private Correspondence, ed. by Richard Lodge. Cambridge: Cambridge University Press.

Lavelee, J. (1845). Historia de España desde los tiempos más remotos hasta el año 1840. Barcelona: Imprenta del Imparcial.

Lee, V. (1887). Studies of the Eighteenth Century in Italy. London: T. Fisher Unwin.

Lemprière, J. (1810). Universal Biography. Vol. 1. New York: E. Sargeant.

Mariano Nipho, F. (1763). Diario estrangero. Noticias importantes, y gustosas para los verdaderos apasionados de Artes, y Ciencias. Gabriel Ramírez, p. 100.

Martín Sáez, D. (2018). La leyenda de Farinelli en España: Historiografía, mitología y política. Revista de Musicología, 61(1), pp. 57-97. https://doi. org/10.2307/26452312.

Martín Sáez, D. (2019). La apoteosis de Farinelli en España. El mito de la superestrella a través de la prensa británica del siglo XVIII. Diagonal: An Ibero-American Music Review, 4(2), pp. 48-75. https://doi.org/10.5070/D84247241.

McGeary, T. (2002). Farinelli and the Duke of Leeds: 'Tanto mio amico e patrone particolare'. Early Music, 30(2), pp. 202-205, 207-210 y 212-213. https://doi. org/10.1093/em/XXX.2.203.

McGeary, T. (1998). Farinelli in Madrid: Opera, Politics, and the War of Jenkins' Ear. The Musical Quarterly, 82(2), pp. 383-421. https://doi.org/10.1093/ $\mathrm{mq} / 82.2 .383$.

McGeary, T. (2005). Farinelli's Progress to Albion: The Recruitment and Reception of Opera's 'Blazing Star'. British Journal for Eighteenth-Century Studies (28), pp. 339-60. https://doi.org/10.1111/j.1754-0208.2005.tb00306.x.

Medina, A. (2011). Los atributos del capón. Imagen histórica de los cantores castrados en España [2001]. Madrid: ICCMU.

Metastasio, P. (1786). Lettere. Vol. III. Nizza: Soc. tip. ed. 
Metastasio, P. (1784). Opere. Vol. XIII. Napoli: Fratelli de Bonis.

Metastasio, P. (1954). Tutte le opere, ed. de Bruno Brunelli. Vol. III. Milano: Mondadori.

Morales, N. (2007). Farinelo à Madrid. Acte premier d'un séjour triomphant: 17371746. En L. Verdi (ed.), I/ Farinelli e gli evirati cantori (pp. 62-63). Lucca: LIM.

Ozanam, D. y Téllez Alarcia, D. (eds.). (2010). Misión en París. Logroño: Instituto de Estudios Riojanos.

Pasquini, E. (2017). 'Respinto da un impensato vento contrario in alto mare': Anton Raaff, il Farinelli e la Storia della musica di Giambattista Martini. Ricercare, 29(1-2), pp. 181-254.

Ribera, A. F. (1855). Farinelli. Zarzuela Histórica en tres actos. Málaga: La llustración Española.

Rodríguez Gutiérrez, B., ed. (2008). Cuentos españoles del siglo XVIII. Madrid: Akal.

Rodríguez Villa, A. (1878). Don Cenon de Somodevilla, Marqués de la Ensenada. Madrid: Librería de M. Murillo.

Sacchi, G. (1784). Vita del cavaliere don Carlo Broschi. Vinegia: Coleti, p. 45.

Sancho Gaspar, J. L. (1998). Los Sitios Reales, escenarios para la fiesta: de Farinelli a Boccherini. En M. Torrione (ed.), Crónica festiva de dos reinados en la 'Gaceta de Madrid' 1700-1759 (pp. 175-196). París: CRIC.

Savage, R. (2005). Getting by with a Little Help from my Twin: Farinelli with Metastasio at his Right Hand, 1747-1759. British Journal for Eighteenth-Century Studies (28), pp. 387-409. https://doi.org/10.1111/j.1754-0208.2005.tb00308.x.

Savage, R. (1998). Staging an Opera: Letters from the Cesarian Poet. Early Music, 26(4), pp. 583-95. https://doi.org/10.1093/earlyj/XXVI.4.583.

Tanucci, B. (1985). Epistolario, ed. de G. de Luca. Vol. V. Roma: Storia e Letteratura.

Tanucci, B. (1984). Epistolario, ed. de L. del Bianco. Vol. IV. Roma: Storia e Letteratura. 
Tanucci, B. (1995). Epistolario, ed. de Maria Claudia Ferrari. Vol. XIV. Roma: Storia e Letteratura.

Tanucci, B. (1990). Epistolario, ed. de S. Lollini. Vol. XI. Roma: Storia e Letteratura.

Tanucci, B. (1985). Epistolario. ed. de M. G. Maiorini. Vol. IX. Roma: Storia e Letteratura.

Tanucci, B. (1980). Epistolario, ed. de R. P. Coppini y R. Nieri. Vol. II. Roma: Storia e Letteratura.

Tanucci, B. (2000). Epistolario. Vol. XVI. Roma: Storia e Letteratura.

Taracha, C. (2001). El marqués de la Ensenada y los servicios secretos españoles en la época de Fernando VI. Brocar (15), pp. 109-122. https://doi.org/10.18172/ brocar. 1850.

Torrione, M. (1996). La casa de Farinelli en el Real Sitio de Aranjuez: 1750-1760 (nuevos datos para la biografía de Carlos Broschi). Archivo español de arte, 69(175), pp. 323-333. https://doi.org/10.3989/aearte.1996.v69.i275.601.

Valente, M. (2007). II canto di Farinelli e di Metastasio a Vienna. En L. Verdi (ed.), II Farinelli e gli evirati cantori (pp. 125-156). Italia: LIM.

Withof, P.-L. (1756). Dissertation sur les eunuques. Duisbourg: Boettiger.

Wraxall, N. W. (1815). Historical Memories of My Own Time. Vol. I. London: T. Cadell \& W. Davies. 


\section{ANEXO}

[1754.] BNE Mss/5709, ff. 1-11 íntegros y fragmentos de f. 12, f. 22 y f. 24 (menciones a Farinelli). Entre corchetes, añadidos de BNE Mss./11038; a pie de página, omisiones y divergencias.

RELACION. Y ULTIMA DESGRACIA DE LA MONARQUIA DE ESPAÑA baXo él GOVIERNO DE DON ZENÒN SOMODEVILLA, MARQUÉS DE LA ENSENADA, QUE DURò DE EL año de 1743 que por muerte de Don Joseph del Campillo ENTRò a LOS MANEJOS DE LA REAL HACIENDA DE INDIAS, GUERRA Y MARINA, HASTA EL 21 DE JULIO DE 1754, QUE FUE DEPUESTO DE TODOS SUS EMPLEOS, Y DESTERRADO A LA CIUDAD DE GRANADA.

Don Zenòn de Somodevilla (despues Marques de la Ensenada) [nacio en Santo Domingo de la Calzada Pueblo de Castilla la Vieja de Padres honrrados aunque Pobres, por cuya razon el suyo exercia en dicho Pueblo el empleo de Maestro de primeras letras. Luego que tubo uso de razon empezo a dar muestras de un espiritu grande y en todo perspicaz, aunque agregandosele las prendas personales de que le doto naturaleza conponian el todo de un sugeto abil y digno de todo aprecio: Este conocimiento le hizo salir de la estrechez de su patria a buscar en las agenas aquella boluble deidad conocida con el nombre de fortuna, y en efecto si como la allo propicia, la ubiera allado constante, ocupara el mexor lugar entre los grandes Privados de que hacen mencion las historias; pero esperimento sus rebeses à exemplo de aquellos cercenandole una bez, y costandole otras las alas con que pretendia remontarse a la cumbre de la inmortalidad, o vibir siempre en la memoria de los hombres doctos, y amantes de la Patria] tubo su primer destino en uno de los Entretenimientos, o Plaza de Escriviente, en los oficios de Marina de Cadiz, en cuia linea continuo [por algun tiempo], sin hacer pie fixo en ella, ni en otra alguna huiendo siempre de toda sugecion, y fatiga: a esto dio motivo la Complexion de su Espiritu, ocupado con variedad en ${ }^{41}$ Exteriores lucimientos, ornato de su Persona, [le fueron proporcionando algunas conexiones de balimiento que de uno y otro adelantamiento ayudada] y pueriles diversiones, ${ }^{42}$ qual poseyò en orden, al Gobierno unas especies generales que como mal digeridas, y solo pasageras, no llegaban á perfeccion en materia àlguna. De este primer destino pasò à otros subalternos, en la misma Clase, hasta que se le confiò la secretaria de Almirantazgo, que obtubo el serenisimo señor Infante

${ }^{41}$ La frase «sin hacer pie fixo en ella, ni en otra alguna huiendo siempre de toda sugecion, y fatiga: a esto dio motivo la Complexion de su Espiritu, ocupado con variedad en» no aparece en Mss./11038, donde leemos "pero su espiritu ocupado en grandes ideas, sin olbidar los...».

42 La frase «y pueriles diversiones» no aparece en Mss./11038. 
Don Phelipe. ${ }^{43}$ En esta ócupacion [(dicen) que] trabajó poco, porque à la sombra de un Personage, tan superior, le facilitò la inclusion con Gentes de Carácter, y particularmente el Cortejo de las Damas, á quienes obsequiaba, ocupando el tiempo en debaneos, de manera que por esta regla, y de repetidas generosas demostraciones, pudo su quasi domestico trato, hacerle mucho lugar en la Confusion de Corte, donde los áctos exteriores, y la Lisonja, equivocando las ácciones, prefieren a la verdadera entidad $y$ al mérito.

Haviendo conferido èl Rey à Don Joseph del Campillo, ${ }^{44}$ en el año de 1741 los manejos de su Real Hacienda y la Secretaria de Guerra, Indias, y Marina, se dio principio con la muerte del Emperador Carlos 6을 à la Expedicion de Italia, con el fin de colocar Rey de Lombardia, àl Señor Infante, con auxilio de la Francia, y con este motivo se acercaba frecuentemente à este ministro, a quien asistió en una grave Enfermedad que padeció, suponiendo se lo mandaban los Reyes. Asi se fue haciendo màs visible, y en la desconfianza de que pudiese servir Campillo, se hacia sensible su falta, en ocasion tan critica; pero aprobechandose Don Zenón de ella, manifestò, que si por tal caso llegase, le havia yà manifestado sus ideas, y las providencias que tenia yà proyectadas, para tan arduo empeño, y que nada debia dar Cuidado, porque el estaba enterado de todo.

Difundio estas artificiosas voces en Palacio, que entonadas por la Marquesa de Torrecuso, Camarera mayor de la Reina ${ }^{46}$ su gran Protectora, ${ }^{47}$ y à quien havia cortejado, y regalado mucho, prepararon el ánimo del Rey con estas èspecies anticipadas.

Salió en fin, Campillo de su àccidente, y se dio orden al Infante, para que pasase àl Exercito, a quien siguiò Don Zenon de secretario suio. ${ }^{48}$

Como su Alteza llevò èl mando de la tropa, y tomó desde luego posesion del Estado de Parma, y Plasencia (que havia recahido en la Reyna Isabel su madre) para de alli continuar los progresos proyectados en Italia; seguia Don Zenón la precisa correspondencia con Campillo en orden à Caudales, para subsistencia de la tropa, y con este motivo se iba interesando mas, y àprovechando las ócasiones, para no malograr sus fines.

Muriò, pues, Campillo improvisamente en Abril de 1743 en ocasion tan critica, como la de una Expedicion pendiente del mayor Empeño; por cuia razòn sintio el

${ }^{43}$ Felipe I de Parma (1720-1765).

44 José Campillo y Cossío (1693-1743).

45 Carlos VI (1685-1740), emperador del Sacro Imperio Romano Germánico desde 1711 hasta su muerte.

${ }^{46}$ Laura Castelví y Coloma, marquesa de Torrecuso y camarera mayor de la reina Isabel de Farnesio.

47 Isabel de Farnesio (1692-1766).

48 Secretario de Estado y Guerra del Infante. 
Rey Felipe ${ }^{49}$ su falta, y discurriendo en succesos suio; cuia provision, que en el dia debia ser por las circunstancias la màs premeditada, la hizo la misma Camarera mayor Marquesa de Torrecuso, diciendo àl Rey, que nadie estaba más enterado que Don Zenon, de los proyectos, y Pensamientos de Campillo, ni era tan a proposito para el desempeño; lo que basto, para que sin màs Consulta, sè verificasen en el los Empleos; notese por quanto pueda la casualidad cerca de los Principes, y los daños que ocasiona la falta de Consenso y Comunicación de los tribunales en estos, y los demàs casos de gravedad, por el Comun interes del Reyno.

Diosele luego aviso de su Elevacion, vino en Posta dejando en su lugar cerca de su Alteza, à Don Agustin de Ordeñana, ${ }^{50}$ oficial mayor de aquella secretaria; llego en mayo siguiente tomò posesion, y hallò el Erario con mucho fondo, para continuar la Expedicion, porque fuera de la renta ordinaria de Castilla y socorros, que haviendo venido de Indias, se havian usado Extraordinariamente de diferentes arvitrios, como la Decima, sobre precio de la Sàl, valimientos de mitad de sisas; y arvitrios, Beneficios de Empleos y otros medios que facilitò la industria, y justificó la necesidad esto ádemás del Caudal, que existia en poder de los Thesoreros de Italia, Cataluña, y otros, que todo Estaba preparado, y se fue remitiendo en Especie de oro, y Plata; con que no tuvo que fatigarse, ni trabajar él dicurso, en la manutenicion del Exercito que era el objeto del dia, porque nada sobraba tanto como dinero; y en fin, corroboraron esta Eleccion, los Palaciegos Italianos, que en aquel dia era el Partido Dominante, quienes solo acreditaban para el manejo de los negocios de Hacienda á áquellos que galantemente la regalaba con desperdicio, nò a quien pudiese cuidarla con inteligencia, y prudente économia.

Empero, pues a servir con viento favorable cifrando en los muchos Caudales que encontró, y álgunos quantiosos socorros, que no obstante la Guerra, vinieron de la America, en que tubo poco que trabaxar él discurso, Empleando el tiempo en cortejar Damas, y regalar con preciosas dádivas, àquellos medios, y conductos conducentes a su Conservacion, y particularmente al Capòn, ${ }^{51}$ cuia amistad, comprò à buen precio.

${ }^{49}$ Felipe V (1683-1746).

${ }^{50}$ Agustín Pablo Ordeñana y Goxenechea (1711-1765), colaborador de Ensenada.

${ }^{51}$ Carlo Broschi Farinelli (1705-1782) llegó a España en 1737, convirtiéndose en una figura esencial de la corte de Felipe $V$ e Isabel de Farnesio. Permaneció junto a ellos hasta la muerte de Felipe V en 1746, continuando junto a Fernando VI y Bárbara de Braganza desde ese año hasta la muerte del rey en 1759. Este documento se referirá, sobre todo, al segundo reinado, en el que se ocupa de organizar los festejos reales, incluyendo las óperas del Retiro (dirección, contratación, alojamiento y manutención de los artistas, pagos, entrega de regalos, cuidado del teatro, etc.), las serenatas de Aranjuez y los famosos paseos marítimos por el río Tajo (disposición de los barcos, lista de invitados, caza, músicos, iluminación del río, etc.). Como es sabido, Farinelli se embarcaba en la misma embarcación que los reyes, donde se había dispuesto un clave, y cantaba mientras los reyes (generalmente, la reina) tocaban el clave. 
Así continuo hasta el dia 9 de Julio de 1746 en que murio Felipe $V$ con cuio motivo, haviendo succedido en la Corona su Hijo y heredero nuestro amado Fernando ${ }^{52}$ se contemplò Excluido de los manejos, pues contandose solo con el Marques de Villarias, ${ }^{53}$ que a la sazon era Secretario de Estado para establecer el nuevo Govierno la inaccion, y limitacion de este Ministro, y su poco Espiritu, dio tiempo para que Don Zenòn inspirase à la nueva Reyna por medio del Capòn, se intentaba establecer Consejero de Estado y que seria el medio si no lo Embarazaba de su privada S. M. de tener parte en el Gobierno por que todo lo mandaria el Consejo.

Sento bien la especie, y àprobechandose la Reyna del àbuso le abrio la Puerta y fuè admitido al Despacho afianzado yá en tan alta proteccion, para caminar viento en Popa.

Desde aquí empezò à tirar sus lineas y à reconocer aquel Campo interior; ya que se vio dentro, y haviendo observado que el Capòn conseguia la Gracia de los Reyes, por medio de sus operarios festejos, procuro adquirir la suia, sin que su propio Caudal le costase un quarto; porque teniendo a su arvitrio todo el Herario, jamàs tubo reparo en dar de el para sus fines con mas extension y libertad que si fuere suio.

Por esta regla, lisongeò tambien con mercedes, gratificaciones, pensiones secretas, à todos los demás sugetos que servian cerca de los Reyes, en los quales, no solo daba su conservacion, sino que todos, y cada uno le servia de Espia, para entender las inspiraciones, y conversaciones de los Reyes, que estos milagros, teniendo la bolsa abierta, los hace facilmente qualquiera, que maneja a su arvitrio dinero ageno.

Por estos, y otros quantiosos considerables desperdicios, pedia à los tesoreros mas graves gruesas Cantidades, con el titulo de Gastos Secretos del real servicio, las quales depositaba en Persona de su Confianza, sobre quien le parecia, de manera, que con este galante cebo, fue formando un Partido tan formidable, y numeroso, que puso terror à todo hombre de juicio, y autoridad, que sabia esta tramoya.

Al Capòn concediò letra abierta sin obligacion de dar quenta, para que con el titulo de gasto de òperas diese quanto Caudal quisiese; hacialas ensayar en su Casa para que los Reies entendiesen, quanto se esmeraba en dar gusto, y lo ponderaban los lisonjeros, sobornados con razon porque cada uno tenia un Maiorazgo, fundado en la hipoteca de su manutencion, y asi cuidaban mucho de ella.

Por estos medios, y Caminos, ya dueño del terreno, y cogidos todos los puntos de la soberania, quedaron inutiles las Audiencias del Rey; de manera que al que justamente se quejaba de agravio recivido, o injusticia padecida, solo le quedaba el

52 Fernando VI (1713-1759). El Mss/11038 no se refiere al «amado Fernando» sino a «su hijo Fernando el 6».

53 Sebastián de la Cuadra y Llarena, Marqués de Villarías (1687-1766), secretario de Estado de Felipe V (1683-1746). 
recurso a Dios porque en lo humano no lo tenia; grave ofensa a un Monarca Catolico, y rara desgracia de vasallos.

El Capòn que era sugeto de Capacidad, y no se apartaba del lado de la Reyna, por la aficion que Su Majestad tenia a la musica, se esmeraba en raras invenciones, disponiendo luminarias en el sitio de Aranjuez con increible numero de luces, cuya claridad convertia la noche en dia, distribuidas con Arte, y simetria en su frondosidad, a que concurrian mucha variedad de Musicos, Instrumentos a trechos, y alternando entre si, suspendian el entendimiento.

Hacia venir de Italia a las Cantarinas mas celebres, y sobresalientes, para que la novedad empeñase, y luciese oficio la diversion; y como en lo pasado se esperaba con impaciencia la Posta de Cadiz, con aviso de haver arrivado al Puerto, flota, Galeones, y otros Navios de Caudales de la America, aun más se celebraba el arrivo de ellas, de modo, que del caudal de los vancos se las abiaba.

En Barcelona se daban con anticipacion, las ordenes para recivirlas, y cortejarlas; de Madrid se atropellaban los tiros para conducirlas, mas que si fuera un Capitan famoso, en la noticia de haverse ganado una gran Batalla, y su alojamiento en la Corte era de quenta del Rey, con el servicio, y equipaje necesario, a que seguia una gran demostracion al tiempo de la Prueba, y la crecida asignacion de sueldo, que se sabe, con que los Caudales se invertian en musicos y danzantes.

Aiudaba la diversion don Zenon (que este era su oficio) convirtiendo en mar el Rio Tajo en Aranjuez para el Embarco de los Reyes, suspendiendo el aceso de las aguas; y haciendo otras obras de suma costa para la Navegacion, en que se trajo de los Puertos marineria, que hiciese las faenas correspondientes, y como el Rey era tan aficionado a la Caza de Lobos, los tenian recojidos con anticipacion, para acercarlos a la orilla del Rio (suponiendo los monteros una Batida) y los tirase desde la Embarcacion; o Principes, propiamente esclavos, y Cautivos de la Lisonja! y el engaño que difunde la adulacion en vuestras generosas reales acciones, y que irreperables daños causa al Comun del Reino privando a los Vasallos de los efectos de vuestra Real Clemencia, y innata Piedad! O infeliz de los causantes, cuia ambicion los precipita, y hace reos en el tribunal de ambas magestades, y responsables a unos daños y perjuicios irreparables por su generalidad, y trascendencia.

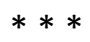

$\underline{\text { Paz del año de } 1748}$ 
Como el principal cuidado le fundaba en los lucimientos de su Persona, a titulo de la Paz, obtubo el Toysòn de oro, Gran Cruz de Malta, y otros honores, en que daba testimonio de la satisfaccion con que y quan asegurado estaba en la Real confianza, y haviendo concurrido el Capon, a la inspiracion de semejante gracia, en buena correspondencia, despues de Enrriquecerle, dispuso que el Rey le concediese una Merced de avito en la orden de Calatrava, de que se le hicieron pruebas, y armo Caballero en el convento de Calatrava de esta Corte, Prueba del Poder de un monarca, y de la insolencia de un ministro insolente.

\section{$[\ldots]$}

12. [no 13 en Mss/1962 y Mss/11038]

Haviendo supuesto el Capòn (protector de Don Zenon) que en Inglaterra le confiscaron sus vienes, por haverse quedado en España valuò esta perdida en 180000 Pesos, que se librò [a su favor] reservadamente y puso en el Comercio de Indias.

\section{$[\ldots]$}

18. [no 19 en Mss/1962 y Mss/11038]

Aun que parecia buen Christiano, no se le conocio Confesion, pero el del Rey, que era dueño de sus acciones, le sobstenia, y proclamando, que no habia en Europa un Ministro semejante, sin el que no se podia vivir, cuio eco percivia el monarca ocultando las ordenes, y el infeliz estado de los vasallos y del Reino y que todo era notorio. En esto miraba a su propia conservacion, lisongeando a la pobre Reina que con estas Especies, y bajo influxos del Capon vivia engañada, y con ignorancia del estado de la Monarquia.

\section{$[\ldots]$}

[Esto es lo que se obserbo hasta el dia 20 de Agosto del propio año expresado, en que se escribe esto] 
Página intencionadamente en blanco. 